\title{
WILEY-VCH
}

DOI: $10.1002 /(($ please add manuscript number))

Article type: (Review)

\section{D materials beyond graphene for high-performance energy storage applications}

Xiaoyan Zhang, Lili Hou, Artur Ciesielski and Paolo Samori*

ISIS \& icFRC, Université de Strasbourg \& CNRS, 8 allée Gaspard Monge, 67000 Strasbourg, France

Email: samori@unistra.fr

Keywords: layered materials, energy storage, supercapacitors, batteries

Energy crisis is one of the most urgent and critical issues in our modern society. Currently, there is an increasing demand for efficient, low-cost, light-weight, flexible and environmentally benign, small-, medium-, and large-scale energy storage devices, which can be used to power smart grids, portable electronic devices, and electric vehicles. Novel electrode materials, with a high energy density at high power are urgently needed for realizing high-performance energy storage devices. The recent development in the field of 2D materials, including both graphene and other layered systems, has shown promise for a wide range of applications. In particular, graphene analogues, due to their remarkable electrochemical properties, have shown great potential in energy-related applications. This review aims at providing an overview of current research and important advances on the development of $2 \mathrm{D}$ materials beyond graphene for supercapacitors and batteries. The major challenges to be tackled, and more generally the future directions in the field, are also highlighted. 


\section{WILEY-VCH}

\section{Introduction}

The exhaustion of fossils fuels and climate change are among the greatest problems faced by our modern society. To counteract the growing energy consumption demand, there is an urgent need to design sustainable, efficient and low-cost devices for energy production and storage. Being confronted with the colossal energy requirements against the backdrop of global warming and the looming energy crisis, the development of clean and renewable energy materials as well as their devices is highly desirable. Harnessing renewable energy sources such as sunlight or wind is a first consideration for sustainable energy production. However, they are diffuse and intermittent, owing to the unreliability of nature. Conversely, tidal power and wave energy rely on a constant flow thus are more predictable and abundant, yet, likewise geothermal energy, they can only be produced at selected sites; the collection of the generated energy and its transmission is unfortunately a big hurdle towards these technologies. These drawbacks have stimulated the research on efficient energy storage devices featuring high-energy capacity and excellent cycle performance. Energy storage devices such as supercapacitors and batteries, with high power/energy densities, are expected to play essential roles in our daily life as the dominant power sources for portable consumer electronics (e.g., smartphones, tablets, notebook PCs and camcorders), hybrid electric/plug-inhybrid vehicles and smart grids. ${ }^{[1-6]}$

The recently increased research efforts on 2D materials, i.e., graphene and its analogues, is to a great extent the result of the promise that they hold for technological applications including electronic devices, sensors, catalysts, energy conversion and storage devices, etc., by taking full advantage of their outstanding electrical, optical, chemical, and thermal properties. ${ }^{[7-14]}$ Beyond graphene, other layered materials possessing various elemental compositions and different crystallographic structures, offer a broad portfolio of material's solutions with tunable chemical and physical properties for application as high-performance active components, which can operate as electrode materials for high-performance electrochemical 


\section{WILEY-VCH}

energy storage devices. ${ }^{[4,15,16]}$ Although graphene-based nanomaterials have demonstrated outstanding performance as electrodes in energy storage devices, new alternative nanomaterials should also be developed in order to further improve the electrochemical performance. Other 2D materials as graphene analogues (GAs) are expected to have broad implications in next generation of clean, efficient, and renewable energy systems. Layered materials of GAs refer to layered materials having similar structure as graphene, with planar topology and ultrathin thickness (single to few atomic layers). Typical GAs for energy storage include transition metal dichalcogenides (TMDs), transition metal oxides (TMOs)/hydroxides (TMHs), metal sulfides, phosphorenes, MXenes, silicences, etc (Figure 1). ${ }^{[1]}$

\section{Insert Figure 1 here}

Due to their thickness on the atomic scale, their inherent properties differ from those of their bulk lamellar systems. In particular, the quantum confinement of electrons in the $2 \mathrm{D}$ plane imparts them with unprecedented electrical and electronic characteristics (Table 1). ${ }^{[18-26]}$ Moreover, it is well known that the delivered specific capacity of electrode materials is closely related with the reaction kinetics during the charging/discharging process. ${ }^{[3]}$ In view of their high surface-to-volume ratio, GAs offer high specific surface areas (Table 1) to enable full utilization of all available sites of active electrode materials. ${ }^{[27-30]}$ As a result, the exposed contact area is significantly enhanced between the electrodes and electrolytes, and also the paths for transport of charges are largely shortened. Last but not least, GAs also exhibit excellent electrochemical properties. ${ }^{[31]}$ All of these characteristics make them potential candidates for energy storage devices.

\section{Insert Table 1 here}

In this contribution, after a brief introduction on the preparation methods of GAs, we review the most enlightening recent progresses of GAs in energy storage devices, providing outlooks and perspectives of this topical area of science and technology. 


\section{WILEY-VCH}

\section{Preparation methods of GAs}

Since there are already several excellent review articles discussing the unique properties of layered materials beyond graphene, ${ }^{[32-37]}$ in the present review we will not focus on their properties. Prior to discussing applications in supercapacitors and batteries, we briefly introduce the methods for the preparation of GAs. The reliable production of high-quality atomically thin $2 \mathrm{D}$ systems and the fine-tuning of their various properties through scalable approaches is a crucial first step for realizing devices for energy storage. Hitherto, two approaches have been pursued to obtain monolayer-thick GAs sheets, i.e., the top-down and bottom-up strategies (Figure 2). The former relies on the chemical ${ }^{[38]}$ or mechanical ${ }^{[39-41]}$ exfoliation of bulk crystals into individual sheets; the latter allows the generation of GAs from atoms or suitably designed molecular building blocks, which upon chemical reactions form covalently linked GAs sheets. ${ }^{[42]}$

\section{Insert Figure 2 here}

\subsection{Top-down approaches}

The top-down approaches enable the production of micrometer- and/or nanometer-sized sheets from bulk crystals. On the one hand, it is generally assumed that the GAs sheets produced via mechanical cleavage (scotch tape method) possess highest quality and purity, which makes them suitable for fundamental research, and in particular for realization of proof-of-concept devices. ${ }^{[43]}$ Yet, mechanical cleavage is unsuitable for mass production due to the low yield and lack of control over the number of layers in the exfoliated samples. On the other hand, large quantities of mono- and few-layer thick GAs sheets, characterized by a low content of structural defects, can be obtained by exploring top-down methods such as ultrasound-induced liquid-phase exfoliation $(\mathrm{UILPE})^{[44-47]}$ or electrochemical liquid-phase exfoliation (ELPE), ${ }^{[48-52]}$ which are extremely versatile and can be carried out in a variety of environments. Other methods, which combine intercalation of bulk crystals with chemical inserts and its subsequent exfoliation, are also being developed. ${ }^{[53]}$ 


\section{WILEY-VCH}

\subsection{Bottom-up approaches}

The bottom-up production of large-area GAs with specific number of layers can be achieved by making use of chemical vapor deposition (CVD) techniques. ${ }^{[54]}$ Among the CVD methods, sulfurization (or selenization) of metal (or metal oxide) thin films is being extensively explored. ${ }^{[55,56]}$ Another useful method is to synthesize 2D materials using molecular precursors via a wet chemical hydrothermal/solvothermal treatment. For instance, GAs like TMOs can be produced via self-assembly, where amphiphilic block copolymers and shortchain alcohol co-surfactants are employed as structure-directing agents to confine the stacking and growth of the metal oxide precursor oligomers along the chosen direction. ${ }^{[57]}$

As for energy storage, UILPE ${ }^{[39,44-46]}$ and wet chemical synthesis ${ }^{[57]}$ are the most commonly used approaches for the preparation of layered materials of GAs, owing to the advantages discussed above as well as of easy and large-scale preparation.

\section{Supercapacitors}

Supercapacitors, also named as electrochemical capacitors, have attracted tremendous research interest during the past decades, primarily due to their high power density, rapid charging/discharging, and excellent cycle stability. ${ }^{[2]}$ Undoubtedly, supercapacitors provide a promising approach to resolve the current energy demand by allowing fast storage of intermittent renewable energy. Based on the underlying energy storage mechanism, supercapacitors can be divided into two types: electrical double-layer capacitors and pseudocapacitors. ${ }^{[58]}$ The performance of supercapacitors can be evaluated by using the following parameters: i) mass/volume capacitance, ii) energy/power density, and iii) cycle lifetime. The unique characteristics that make a material suitable as an active electrode include good electrical conductivity, high specific surface area, optimized pore size 


\section{WILEY-VCH}

distribution, as well as proper introduction of doping, which determine the final performance of supercapacitors. ${ }^{[59]}$ Moreover, other factors like the choice of electrode configuration, electrolytes, mass loading, voltage applied, etc., also play an important role in the outcome of supercapacitors. ${ }^{[3]}$ The progress in supercapacitor technologies can surely benefit from the development of novel nanostructured electrode materials. ${ }^{[59]}$ Presently, intensive research efforts on supercapacitors are devoted towards developing/discovering new electrode materials with enhanced energy storage capability and a long cycle life, meanwhile reducing cost to realize their extensive usage in our daily life.

\subsection{Electrical double-layer capacitors}

In electrical double-layer capacitors (EDLCs), the capacitance arises from the adsorption of both positive and negative ions in a double layer at the electrode/electrolyte interface; therefore, it is highly dependent on the specific surface area of the electrode materials that is accessible to electrolyte ions. During the charging process, negative ions move to the positive electrode, while positive ions transfer towards the negative electrode (Figure 3). The direction of ions movement is reversed in the discharging process. ${ }^{[58]}$ Typically, the electrodes

used in EDLCs are composed of porous carbon-based materials, ${ }^{[60,61]}$ including activated carbon, ${ }^{[62]}$ mesoporous carbon, ${ }^{[63]}$ carbon nanofibers, ${ }^{[64]}$ carbon nanotubes, ${ }^{[65]}$ graphene, ${ }^{[66]}$ and carbide-derived carbons. ${ }^{[67]}$

\section{Insert Figure 3 here}

GAs with high electric conductivity would be of high interest and of significance for fabrication of supercapacitors. However, semiconducting GAs such as $\mathrm{MoS}_{2}$ or $\mathrm{WS}_{2}$ possess relatively low electrical conductivities, ${ }^{[68,69]}$ which hampers their use as electrodes in supercapacitors. To overcome this problem, Chhowalla and co-workers reported an approach to prepare chemically exfoliated sheets of $\mathrm{MoS}_{2}$ using organolithium compounds with a high concentration of the metallic 1T (stands for a trigonal unit cell consisting of single-layer) 


\section{WILEY-VCH}

phase. ${ }^{[70]}$ The metallic $\mathrm{MoS}_{2}$ sheets with electrical conductivity values of $10^{3}$ to $10^{4} \mathrm{~S} \mathrm{~m}^{-1}$, can be electrochemically intercalated by ions such as $\mathrm{H}^{+}, \mathrm{Li}^{+}, \mathrm{Na}^{+}$and $\mathrm{K}^{+}$with very high efficiency. The as-fabricated supercapacitors without binders and other additives can achieve specific volume capacitance values ranging from $\sim 400$ to $\sim 700 \mathrm{~F} \mathrm{~cm}^{-3}$ in a variety of aqueous electrolytes. In addition, they also showed that $1 \mathrm{~T} \mathrm{MoS}_{2}$ is suitable for high-voltage $(3.5 \mathrm{~V})$ operation in organic electrolytes (Figure 4, a-c), with high volumetric energy and power density values, coulombic efficiencies in excess of 95\%, and good stability over 5,000 cycles. As evidenced by X-ray diffraction analysis, these favourable electrochemical properties of $1 \mathrm{~T} \mathrm{MoS}_{2}$ sheets are mainly the result of their hydrophilic nature and high electrical conductivity, as well as the ability of the exfoliated layers to dynamically expand and intercalate the various ions. It is known that the transition metal of Mo center can exhibit oxidation states from +2 to +6 , rendering it pseudocapacitive abilities like $\mathrm{RuO}_{2}$. In this case, besides EDLCs, there is also some contribution from charge transfer (pseudocapacitance), as evidenced by Nyquist plots. In another study, Bissett et al. prepared $\mathrm{MoS}_{2} /$ graphene nanocomposites, used them as active materials in supercapacitors and they observed a transition from EDLCs to pseudocapacitance in the charge storage mechanism. ${ }^{[71]}$ Tour and co-workers attributed the storage mechanism of $\mathrm{MoS}_{2}$ nanoporous films as a combination of both EDLCs and pseudocapacitance. ${ }^{[72]}$ Soon and Loh pointed out that besides double-layer capacitance, diffusion of the ions into the $\mathrm{MoS}_{2}$ films at slow scan rates gives rise to faradaic capacitance, which enhances the capacitance significantly. ${ }^{[73]}$ However, the exact storage mechanism of $\mathrm{MoS}_{2}$ requires a further in-depth studies in order to be fully unravelled.

\section{Insert Figure 4 here}

As alternative, another member of the TMD family such as vanadium disulfide $\left(\mathrm{VS}_{2}\right)$ has been also exploited. $\mathrm{VS}_{2}$ crystals are composed of the metal V layers sandwiched between two sulfur layers and stacked together by weak van der Waals interactions. $\mathrm{VS}_{2}$ is one of the TMDs which has been only recently explored: it possesses metallic electrical behaviour, 


\section{WILEY-VCH}

rendering it interesting for application as high-performance electrodes for supercapacitors. In a recent study, Xie and co-workers developed a unique ammonia-assisted chemical strategy to exfoliate bulk $\mathrm{VS}_{2}$ flakes into ultrathin metallic $\mathrm{VS}_{2}$ sheets of less than five layers, which can be assembled into thin films via a vacuum filtration process and further used as electrode active materials to construct planar supercapacitors (Figure 4, d-f). ${ }^{[74]}$ The highly conductive $\mathrm{VS}_{2}$ thin film not only prompts ion transport during the charge/discharge process, but also brings a small series resistance inside the electrodes. The cyclic voltammetry (CV) curves showed near-rectangular shapes at different scan rates and no obvious redox peaks were observed, attributed to typical double-layer capacitor behaviors by the authors. However, in this case, the contribution from pseudocapacitance cannot be totally ruled out since rectangular $\mathrm{CV}$ curves are not only related to EDLCs $\left(\mathrm{MnO}_{2}\right.$ also shows rectangular $\mathrm{CV}$ curves, but is a typical pseudocapacitive electrode material). In-situ X-ray absorption spectroscopy (XAS) or other techniques that allow monitoring changes in the valence state of elements are needed to find out the exact storage mechanism. Importantly, the as-fabricated $\mathrm{VS}_{2}$ in-plane supercapacitors displayeds a specific capacitance as high as $4760 \mu \mathrm{F} \mathrm{cm} \mathrm{cm}^{-2}$ with no obvious degradation after 1000 charge/discharge cycles, thereby opening the door to the design of in-plane supercapacitors with high performance based on layered materials for the practical power sources in advanced intelligent devices.

\subsection{Pseudocapacitors}

In contrast to EDLCs, pseudocapacitors store energy through fast and reversible faradaic redox reactions with charge transfer occurring at or near the electrode surface (Figure 5). ${ }^{[58]}$ Pseudocapacitive electrode materials, with reversibly faradic reaction behaviour, are of great research interests. The amount of electric charge stored in pseudocapacitors is linearly proportional to the applied voltage. When an external potential is applied, the active electrode materials undergo reversible redox reactions, generating charges and resulting in faradaic 


\section{WILEY-VCH}

current passing through the cell of supercapacitors. Since the specific capacitance depends on the faradaic charges generated at or near the electrode surface, it is very important to use pseudocapacitive electrode materials with high charge generation and storage ability in a short period of time. The most widely used pseudocapacitive electrode materials include conducting polymers ${ }^{[75]}$ and TMOs/TMHs. ${ }^{[76-78]}$ Pseudocapacitors can achieve much higher energy densities than EDLCs (10 to 100 times), since they can provide a variety of oxidation states for efficient redox charge transfer reactions between electrodes and adsorbed/inserted electrolyte ions.

\section{Insert Figure 5 here}

Among various materials used as electrodes for pseudocapacitors, TMOs and TMHs have been widely employed due to their large theoretical capacity, ${ }^{[76-79]}$ chemical stability and compatibility with electrolytes, as well as their facile preparation, which are vital to achieve durable and cost-effective energy storage. The electrochemically redox active transition metal layered materials usually possess high specific capacitances, which are favourable for high energy density storage. For example, Zhang et al. prepared thin $2 \mathrm{D}$ sheets of $\mathrm{Co}_{3} \mathrm{~V}_{2} \mathrm{O}_{8}$ via a hydrothermal approach and the as-synthesized sheets were used as an active electrode material in supercapacitors. ${ }^{[77]}$ The assembled device showed a specific capacitance of $739 \mathrm{~F}$ $\mathrm{g}^{-1}$, with a cycle stability of $95.3 \%$ after 2000 cycles at $0.5 \mathrm{~A} \mathrm{~g}^{-1}$. In another case, Xie's group synthesized single layer $\beta-\mathrm{Co}(\mathrm{OH})_{2}$ with five-atoms layer thickness through a facile orientedattachment strategy. ${ }^{[78]}$ An all-solid-state asymmetric supercapacitor fabricated from using single-layer $\beta-\mathrm{Co}(\mathrm{OH})_{2}$ as cathode and nitrogen-doped graphene as anode, exhibited a high energy density of $98.9 \mathrm{Wh} \mathrm{kg}^{-1}$ at a power density of $17981 \mathrm{~W} \mathrm{~kg}^{-1}$, and also excellent cycling life with $93.2 \%$ capacity retention after 10000 charge/discharge cycles.

\section{Insert Figure 6 here}

For energy storage devices, highly conductive active electrode materials are required to realize fast charge diffusion, leading to quick electrical responses and low resistance loss. 


\section{WILEY-VCH}

Therefore, it is crucial to control/optimize the electrical conductivity of the active electrodes in order to achieve high specific capacitance and rate capability. As a typical example, conductive MXenes have been employed as electrode materials for pseudocapacitors, demonstrating a very high volumetric capacitance. ${ }^{[80-83]}$ Gogotsi and co-workers demonstrated a facile strategy for the in situ polymerization of pyrrole confined between conductive $\mathrm{Ti}_{3} \mathrm{C}_{2} \mathrm{~T}_{x}$ layers. ${ }^{[82]}$ Polypyrrole (PPy), as a conductive polymer, can intercalate between the $\mathrm{Ti}_{3} \mathrm{C}_{2} \mathrm{~T}_{x}$ layers increasing the space for rapid charge transport, and can also provide conductive aligned paths for charge percolation. When tested as supercapacitor electrodes, the $\mathrm{PPy} / \mathrm{Ti}_{3} \mathrm{C}_{2} \mathrm{~T}_{x}$ composite displayed a volumetric capacitance of $\approx 1000 \mathrm{~F} \mathrm{~cm}^{-3}$ with capacitance retention of 92\% after 25000 cycles (Figure 6), indicating high electrochemical performance and excellent cycle life. The enhanced capacitance is due to the synergistic effect between the $\mathrm{Ti}_{3} \mathrm{C}_{2} \mathrm{~T}_{x}$ layers and the conductive PPy. The strategy can be used to synthesize other conducting polymer/MXene composites for energy-related application. However, in practice, the low electrical conductivity of most GAs (such as TMOs, TMHs, and TMDs) limits the ion diffusion rate in those electrode materials. As a consequence, their redox reversibility could be affected, notably rendering them inappropriate for high-rate energy storage devices. To solve the problem, combination of GAs with other conductive materials, including graphene, ${ }^{[84-87]}$ carbon nanotubes, ${ }^{[88-90]}$ carbon nanofibres, ${ }^{[91]}$ metals, ${ }^{[92]}$ conducting polymers, ${ }^{[93-96]}$ conductive substrates, ${ }^{[97-100]}$ etc., has been investigated to enhance the overall performance of supercapacitors based on GAs, by taking the advantage of the high conductivity of the conductive scaffolds. Moreover, these strategies may allow more electrolyte ions to penetrate efficiently into the hybrid electrode materials during charging/discharging processes. A remarkable example has been reported by Chang et al. by fabricating asymmetric supercapacitors based on reduced graphene oxide (RGO)/MnO 2 as the anode and $\mathrm{RGO} / \mathrm{MoO}_{3}$ as the cathode. ${ }^{[85]}$ For the anode, mesoporous $\mathrm{MnO}_{2}$ nanospheres exhibit short diffusion path length for both ions of electrolyte and electrons, favouring 


\section{WILEY-VCH}

migration of ions during rapid charging/discharging process. For the cathode, the thin $\mathrm{MoO}_{3}$ sheets support short diffusion path length for ions of electrolyte in the perpendicular direction and continuous transport pathways for electrons in the parallel direction. The introduction of graphene into the two active electrodes further offers extra interface at the hybridized interlayer areas to facilitate charge transport during charging/discharging processes, improving the pseudocapacitive reactions and rate capability. The devices showed a high energy density of $42.6 \mathrm{Wh} \mathrm{kg}^{-1}$ at a power density of $276 \mathrm{~W} \mathrm{~kg}^{-1}$ and a maximum specific capacitance of $307 \mathrm{~F} \mathrm{~g}^{-1}$. Remarkably, the specific capacitance was improved even after 10000 cycles, which is attributed to the development of micropore structures during the repetition of ion transfer.

\section{Insert Figure 7 here}

Light-weight, flexible energy storage devices are highly desirable for portable flexible electronics. Feng et al. fabricated cellulose paper (CP)-based asymmetrical, flexible thin film supercapacitors using graphite $/ \mathrm{Ni} / \mathrm{Co}_{2} \mathrm{NiO}_{4}$ sheets-CP as positive electrode and graphite/Ni/active carbon-CP as negative electrode (Figure 7). ${ }^{[101]}$ The assembled device shows a high volumetric energy density $\left(2.48 \mathrm{mWh} \mathrm{cm}^{-3}, 80 \mathrm{Wh} \mathrm{kg}^{-1}\right)$, a high volumetric power density $\left(0.79 \mathrm{~W} \mathrm{~cm}^{-3}, 25.6 \mathrm{~kW} \mathrm{~kg}^{-1}\right)$ and an excellent cycle stability at different bending states $(<4 \%$ capacitance loss after 20000 cycles). This study gives a good example of design and fabrication of high performance and flexible energy storage devices.

Besides coupling GAs with conductive nanomaterials, other strategies have also been pursued in order to improve the electrical conductivity of the former. For instance, Wang et al. synthesized nickel-cobalt-aluminium layered hydroxides and further chemically treated them with sodium hydroxide yielding enhanced electrical conductivity, which is caused by partial conversion of $\mathrm{Co}^{2+}$ to a more conductive $\mathrm{Co}^{3+}$ state. ${ }^{[102]}$ The obtained layered hydroxides show a high specific capacitance of $738 \mathrm{~F} \mathrm{~g}^{-1}$ at $30 \mathrm{~A} \mathrm{~g}^{-1}$, which is $57.2 \%$ of $1289 \mathrm{~F} \mathrm{~g}^{-1}$ at 1 $\mathrm{A} \mathrm{g}^{-1}$. 


\section{WILEY-VCH}

Insert Table 2 here

As electrode materials for supercapacitors, GAs possess obvious advantages, such as high specific surface areas for ion adsorption, open 2D channels for ion transport, and also large theoretical capacity. However, the low electrical conductivity of GAs limits ion diffusion rates and induces a high resistance loss.

\section{Batteries}

Due to their combination of apparent high surface-to-volume ratio and excellent electrochemical properties, layered materials are also promising candidates for electrodes to be used in batteries. Remarkable progress has been made using GAs in lithium-ion batteries (LIBs), sodium-ion batteries (SIBs), lithium-sulphur (Li-S) batteries and other kinds of batteries. Here we will mainly discuss their applications in LIBs and SIBs.

\subsection{Lithium-ion batteries}

Lithium-ion batteries (LIBs) have been developed quite rapidly since their first commercialization by Sony in 1991, and have become one of the most popular rechargeable batteries with many outstanding features including high energy density, low maintenance, no memory effect, and little self-discharge (only a slow loss of capacity when not in use). ${ }^{[103]}$ LIBs are used as the dominant power source for many portable electronic devices (e.g., cell phones, laptops, digital cameras, etc.), and they are expected to hold great potential for the upcoming large-scale applications (e.g., electric cars and stationary energy backup systems). For LIBs, the electrochemical reaction of lithium ions is realized through different chemical pathways, such as via an intercalation/de-intercalation reaction, conversion reaction and alloying/de-alloying reaction. ${ }^{[103]}$

The working principle of a conventional LIB cell is based on the reversible shuttling of lithium ions, which results in a difference of electrochemical properties between the anode 


\section{WILEY-VCH}

and the cathode. ${ }^{[103]}$ Therefore, the inherent properties of the electrode materials represent a key factor largely affecting the overall performance of LIBs. Hitherto, graphite is still the most widely employed anode material for LIBs due to its flat potential profile, high columbic efficiency, and good cycling performance. ${ }^{[104]}$ However, graphite itself possesses a relatively low theoretical capacity $\left(372 \mathrm{mAh} \mathrm{g}^{-1}\right)$. Furthermore, the slow Li ions diffusion rate of $10^{-8}$ $\mathrm{cm}^{2} \mathrm{~s}^{-1}$ in the graphite structure results in a low power density of LIBs. Thus, there is a need to develop new electrode materials for LIBs. Tremendous efforts are being made to explore alternative anode materials with a higher lithium storage capacity, better rate capability and cycle stability. Numerous candidates including graphene, ${ }^{[105,106]}$ metals, ${ }^{[107]}$ and metal oxides $^{[108]}$ have been investigated, trying to address these challenges. Among them, sheets of GAs have been considered as promising electrode candidates for LIBs to offer the advantages of a larger capacity over traditional graphite anode. Generally speaking, lithium storage based on layered materials benefits from the structural qualities of these nanoscale systems such as their high surface area, large void space and good structural stability.

\section{Insert Figure 8 here}

Sheets of TMOs have been widely exploited as components for LIBs also because they exhibit some advantages such as high specific capacity, good stability, widespread availability, relatively easy to prepare and their environmental friendly nature. Lithium storage in these electrode materials is based on the reversible redox reaction between lithium and transition metal cations, which is termed as "conversion reaction". ${ }^{[109]}$ TMOs such as $\mathrm{Fe}_{2} \mathrm{O}_{3},{ }^{[110,111]}$ $\mathrm{V}_{2} \mathrm{O}_{5},{ }^{[112]} \mathrm{Nb}_{2} \mathrm{O}_{5}{ }^{[113]}$ and $\mathrm{TiO}_{2}{ }^{[114-116]}$ have been used as anodes in LIBs. $\mathrm{Fe}_{2} \mathrm{O}_{3}$, as a typical TMOs, because of its very high theoretical specific capacity of $1006 \mathrm{mAh} \mathrm{g}^{-1}$, it has been considered as a very promising candidate for the next generation of anode materials in batteries. Cao et al. fabricated 3D hierarchical porous $\alpha-\mathrm{Fe}_{2} \mathrm{O}_{3}$ sheets on copper foil using hydrothermal and annealing treatments, and then directly used as a binder-free anode for LIBs

(Figure 8). ${ }^{[110]}$ A good capacity of $433 \mathrm{~mA} \mathrm{~h} \mathrm{~g}^{-1}$ is retained at a high current of $20.1 \mathrm{~A} \mathrm{~g}^{-1}$, 


\section{WILEY-VCH}

and a reversible capacity up to $877.7 \mathrm{mAh} \mathrm{g}^{-1}$ is maintained after 1000 cycles at $2.01 \mathrm{~A} \mathrm{~g}^{-1}$, demonstrating a high reversible capability and outstanding rate performance. The unique porous 3D hierarchical nanostructure enhances the electrochemical performance not only by facilitating the kinetics for Li ions diffusion by shortening the diffusion pathways to the nanoscale due to the large electrode-electrolyte contact area, but also by improving the electrode stability because of the reduced lattice strain associated with lithium intercalation. Moreover, the 3D conductive network based on the conversion reaction mechanism $\left(\mathrm{Fe}_{2} \mathrm{O}_{3}+\right.$ $\left.6 \mathrm{Li} \leftrightarrow 2 \mathrm{Fe}+3 \mathrm{Li}_{2} \mathrm{O}\right)$ is formed during cycling, guaranteeing efficient electron transportation. The in-situ fabricated free-standing and aligned 3D hierarchical nanostructure ensures good electronic contact between the $\alpha-\mathrm{Fe}_{2} \mathrm{O}_{3}$ sheets and the $\mathrm{Cu}$ current collector, which theoretically facilitates electrons flow between the substrate and $\alpha-\mathrm{Fe}_{2} \mathrm{O}_{3}$ flakes. However, in this case, a very low mass loading $\left(0.35 \mathrm{mg} \mathrm{cm}^{-2}\right)$ is used, which might be related with the low tap/packing density of the 3D hierarchical porous $\alpha-\mathrm{Fe}_{2} \mathrm{O}_{3}$ sheets. The use of low mass loading of nanostructured materials leads to devices with moderate performance and limited cycle life. ${ }^{[1]}$ For reliable measurements and practical applications, test cells should have active materials with mass loadings on the order of $10 \mathrm{mg} \mathrm{cm}^{-2}$. For $2 \mathrm{D}$ structure of $\mathrm{TiO}_{2}$, its ease of structural tailoring, its low volume expansion upon lithiation combined with good stability and lack of lithium plating endow this layered material a great potential to be charged/discharged at high current rates for extended cycling. ${ }^{[114-116]}$

\section{Insert Figure 9 here}

Superior to single-phase oxides, the strongly coupled mixed-metal oxides may synergistically enhance the electrochemical properties such as reversible capacity, electrical/ionic conductivity, and also mechanical stability, leading to better electrochemical performance. ${ }^{[117-}$ 121] Wang and co-workers reported a method to prepare $\mathrm{Co}_{3} \mathrm{~V}_{2} \mathrm{O}_{8}$ sheets via a simple hydrothermal method followed by annealing. ${ }^{[17]}$ The sheets based electrodes exhibit outstanding reversible capacity $\left(1114 \mathrm{~mA} \mathrm{~h} \mathrm{~g}^{-1}\right.$ retained after 100 cycles) and excellent rate 


\section{WILEY-VCH}

performance (361 $\mathrm{mA} \mathrm{h} \mathrm{g}^{-1}$ at a high current density of $10 \mathrm{~A} \mathrm{~g}^{-1}$ ) for lithium storage (Figure 9). Detailed studies of the morphological and structural changes of $\mathrm{Co}_{3} \mathrm{~V}_{2} \mathrm{O}_{8}$ upon cycling indicate that reversible conversion reactions between $\mathrm{Co}$ and $\mathrm{CoO}$ are proceeding on the amorphous lithiated vanadium oxides matrixes. The excellent electrochemical performances of the multilayer $\mathrm{Co}_{3} \mathrm{~V}_{2} \mathrm{O}_{8}$ are attributed to the unique morphologies and especially to the surface-to-surface constructions generated during the lithium ion insertion processes. However, it should be mentioned that the first change/discharge cycle shows a low Coulombic efficiency (a high first cycle irreversible capacity loss), due to deconstruction of the $\mathrm{Co}_{3} \mathrm{~V}_{2} \mathrm{O}_{8}$ sheets, formation of amorphous $\mathrm{Li}_{\mathrm{x}} \mathrm{V}_{2} \mathrm{O}_{5}$ and also possible formation of solid electrolyte interface (SEI). This phenomenon has also been observed in other $2 \mathrm{D}$ sheets, ${ }^{[122]}$ which can be suppressed through surface modification. ${ }^{[123]}$

Besides TMOs, TMDs, ${ }^{[124-126]}$ transition metal trichalcogenides $(\mathrm{TMTs}),{ }^{[127]}$ and phosphorenes, ${ }^{[128]}$ other layered materials like transition metal carbides (also named as MXenes) have also been employed as electrodes in LIBs. ${ }^{[129,130]}$ Naguib et al. synthesized 2D niobium and vanadium carbides by selective etching of $\mathrm{Nb}_{2} \mathrm{AlC}$ and $\mathrm{V}_{2} \mathrm{AlC}$ powders in concentrated HF solutions at room temperature, yielding $\mathrm{Nb}_{2} \mathrm{CT}_{\mathrm{x}}$ and $\mathrm{V}_{2} \mathrm{CT}_{\mathrm{x}}$, respectively. ${ }^{[130]}$ When tested as electrodes in LIBs, reversible capacities of 170 and $260 \mathrm{mAh} \mathrm{g}^{-1}$ at $1 \mathrm{C}$, and 110 and $125 \mathrm{mAh} \mathrm{g}^{-1}$ at a high rate of $10 \mathrm{C}$ were obtained after 150 cycles for $\mathrm{Nb}_{2} \mathrm{CT}_{\mathrm{x}}$ or $\mathrm{V}_{2} \mathrm{CT}_{\mathrm{x}}$, respectively, suggesting fast Li diffusion between MXene layers and potential use in high power applications.

\section{Insert Figure 10 here}

As already discussed in the Section 3, single component 2D materials may not meet all the requirements for high rate energy storage devices. Their high reaction activity endows them with relatively good electrochemical performance, however the relatively low conductivity hampers their efficiency. ${ }^{[110-120,124]}$ For example, metal oxide anodes usually possess low rate capability and poor cycling stability owing to inherently poor electronic conductivity, slow 


\section{WILEY-VCH}

reaction kinetics, and severe volume expansion during discharge-charge cycles. ${ }^{[110-120]}$ Therefore, rationally introducing ad hoc functional nanomaterials into single component 2D system may be a route to improve the performance of energy storage devices in terms of capacity, efficiency, activity, and stability, which may origin from the synergetic effect. Layered materials such as TMOs, TMDs, phosphorenes, metal carbides, metal sulfides or silicenes can be combined with RGO/graphene, ${ }^{[131-149]}$ doped RGO/graphene ${ }^{[150-153]} \mathrm{CNT},{ }^{[154-}$ ${ }^{158]}$ conductive carbon, ${ }^{[159-168]}$ carbon nanofibers, ${ }^{[169]}$ carbon nanoboxes, ${ }^{[170]}$ metals, ${ }^{[171]}$ or conducting polymers, ${ }^{[172]}$ generating hybrid electrode materials for LIBs with excellent performance. Dou and co-workers fabricated an atomic layer-by-layer structure of $\mathrm{Co}_{3} \mathrm{O}_{4} /$ graphene and used it as an anode for LIBs. ${ }^{[131]}$ This delicate nanostructure shows very high specific capacities of 2014.7 and $1134.4 \mathrm{mAh} \mathrm{g}^{-1}$ at 0.11 and $2.25 \mathrm{C}$, respectively, indicating excellent rate capability, and also exhibits ultralong cycle life up to 2000 cycles without obvious capacity fading at 2.25 C. $\mathrm{MoS}_{2}$, when used as electrodes for LIBs, still suffers from fast structural deterioration during lithiation/delithiation process and poor electrical conductivity, resulting in pulverization, thus unsatisfactory cycling performance and rate capability. Wang et al. designed a new, robust nanocomposite based on $\mathrm{MoS}_{2}$ and Sdoped RGO through a facile solvothermal approach combined with annealing, and the hybrid is then used as an anode for LIBs (Figure 10). ${ }^{[152]}$ The $\mathrm{MoS}_{2}$ sheets are covalently bridged to S-doped RGO, which is confirmed by X-ray photoelectron spectroscopy (XPS) and density functional theory (DFT) calculations. The intimate contact between the two components guarantees efficient electron transfer pathways. Such a composite shows a superior rate capability of $915 \mathrm{mAh} \mathrm{g}^{-1}$ at $10 \mathrm{~A} \mathrm{~g}^{-1}$, and exhibits a long cycle stability with a capacity of 92.3\% retained after 2000 cycles at $10 \mathrm{~A} \mathrm{~g}^{-1}$. In another example, $\mathrm{Yu}$ and co-workers synthesized carbon nanofibers decorated with $\mathrm{MoS}_{2}$ sheets $\left(\mathrm{CNFs} @ \mathrm{MoS}_{2}\right)$ through a solution coating and a subsequent annealing process. ${ }^{[169]}$ The CNFs@MoS 2 nanofibers show excellent Li storage properties with a high specific capacity (1489 $\mathrm{mAh} \mathrm{g}^{-1}$ upon initial discharge), an 


\section{WILEY-VCH}

excellent cycling performance (1264 $\mathrm{mAh} \mathrm{g}^{-1}$ after 50 cycles) and a good rate performance (860 $\mathrm{mAh} \mathrm{g}^{-1}$ at $5 \mathrm{~A} \mathrm{~g}^{-1}$ ), making it a promising anode material for high-energy LIBs (Figure 11). The synergistic effect between the two components facilitates the formation of a hierarchically conductive network with much improved electrode kinetics and cycling stability.

\section{Insert Figure 11 here}

Other materials like Si also have some drawbacks when exploited as components in electrodes for LIBs, such as their poor electrical conductivity, their large volume change during the lithiation-delithiation process, and serious degradation from unstable solid electrolyte interphase (SEI) layers. Park's group prepared carbon-coated Si sheets via one-step simultaneous molten salt-induced exfoliation and chemical reduction process, and further coated by carbon layers through thermal decomposition in an acetylene atmosphere. ${ }^{[162]}$ The as-fabricated anode shows a high reversible capacity $\left(865 \mathrm{mAh} \mathrm{g}^{-1}\right.$ at $\left.1.0 \mathrm{~A} \mathrm{~g}^{-1}\right)$, an outstanding capacity retention $(92.3 \%$ after 500 cycles at $0.5 \mathrm{C})$, an excellent rate capability (a capacity of $60 \%$ at $20 \mathrm{C}$ compared to $2 \mathrm{C}$ ), and remarkably suppressed volume expansion (42\% after 200 cycles at a rate of $0.2 \mathrm{C}$ ). All the above discussed strategies can be easily applied/extended to design other novel nanocomposites based on GAs/conductive fillers, which hold great promise in next-generation rechargeable LIBs.

\subsection{Sodium-ion batteries}

As lithium resources are relatively expensive and geographically constrained, developing new type of batteries with a high electrochemical performance while a lower cost is highly desirable. Sodium is the second-lightest and -smallest alkali metal next to lithium, and they share common physico-chemical properties. The abundance and low cost of sodium in the earth and its low redox potential (slightly higher than lithium) promote sodium-ion batteries (SIBs) as a promising alternative to LIBs for electric vehicles and grid-level energy storage. 


\section{WILEY-VCH}

The energy density for SIBs is expected to be above $200 \mathrm{Wh} \mathrm{Kg}^{-1}$. SIBs have a similar operation mechanism as LIBs, which potentially provides high reversibility and long cycling life. During charging process, an oxidation reaction occurs at the cathode with $\mathrm{Na}$ de-insertion and electron loss. The sodium ions move to the anode via the electrolyte, and electrons simultaneously transfer to the anode through external conduction path. This leads to a reduction reaction occurring at the anode with $\mathrm{Na}$ insertion. An opposite process occurs during the discharging process. Currently, the low capacity, poor rate capability, and cycling stability of existing anodes significantly hinder the practical applications of SIBs. One major scientific issue for a competitive SIBs technology is to develop viable electrode materials with a high specific capacity and appropriately low redox potentials.

Compared to LIBs, the larger size of sodium ions (1.02 $\AA$ vs. $0.76 \AA$ for lithium ions) hampers the kinetics of electrochemical reactions. Therefore, reversible electrode materials are required to possess large enough channels and/or interstitial sites. Nowadays, layered TMOs and TMDs (such as $\mathrm{MoS}_{2}$ and $\mathrm{SnS}_{2}$ ) have been employed as electrode materials in SIBs. ${ }^{[173-177]}$ The large interlayer distance in TMDs is beneficial to the accommodation of sodium ions. However, due to their low electrical conductivity, the overall performance especially the high-rate capability (kinetic factors such as ion diffusivity and electron conductivity) is still far beyond satisfaction. For example, Wang and co-workers reported a liquid phase exfoliation approach to prepare few-layer thick $\mathrm{MoS}_{2}$ inks and used them as an anode material in SIBs. ${ }^{[176]}$ The $\mathrm{MoS}_{2}$ based electrode only showed a moderate capacity of $530 \mathrm{mAh} \mathrm{g}^{-1}$ at $40 \mathrm{~mA} \mathrm{~g}{ }^{-1}$. Therefore, introducing foreign counterparts with good conductivity holds the potential to solve the problem.

\section{Insert Figure 12 here}

Phosphorus can react electrochemically with sodium to form $\mathrm{Na}_{3} \mathrm{P}$ at an attractive potential, possessing a theoretical specific capacity of $2596 \mathrm{mAh} \mathrm{g}^{-1}$. Cui and co-workers designed a sandwiched nanostructure comprising few-layer phosphorene alternating with graphene sheets 


\section{WILEY-VCH}

(Figure 12). ${ }^{[29]}$ The phosphorene sheets, with an increased interlayer distance, offer a short and effective diffusion path for sodium ions. The hybrid materials show an extremely high capacity of $2440 \mathrm{mAh} \mathrm{g}^{-1}$ at $50 \mathrm{~mA} \mathrm{~g}^{-1}$ with a capacity retention of $83 \%$ after 100 cycles. The high capacity is revealed by in situ transmission electron microscopy and ex situ X-ray diffraction techniques, indicating a dual mechanism of intercalation of sodium ions along the $\mathrm{x}$ axis of the phosphorene layers followed by the formation of a $\mathrm{Na}_{3} \mathrm{P}$ alloy. It is concluded that the graphene sheets not only act as a mechanical backbone and an electrical conductor, but also serve as an elastic buffer space for accommodating the anisotropic expansion upon cycling operation. Besides phosphorene, other layered materials like metal sulfides and TMDs have also been combined with conductive matrix (e.g., RGO/graphene/conductive carbon) for SIBs. ${ }^{[178-188]}$ For instance, Qu et al. designed a $\mathrm{SnS}_{2}-\mathrm{RGO}$ nanocomposites using a facile hydrothermal route from a mixture of tin (IV) chloride, thioacetamide (TAA) and graphene oxide (GO). ${ }^{[179]}$ The as-made electrode showed a high charge specific capacity (630 mAh g ${ }^{-1}$ at $0.2 \mathrm{~A} \mathrm{~g}^{-1}$ ), good rate performance (544 $\mathrm{mAh} \mathrm{g}^{-1}$ at $2 \mathrm{~A} \mathrm{~g}^{-1}$ ) and long cycle-life (500 mAh $\mathrm{g}^{-1}$ at $1 \mathrm{~A} \mathrm{~g}^{-1}$ for 400 cycles). The good performance is attributed to the increased interlayer spacing of $\mathrm{SnS}_{2}$, which could better accommodate the volume change in $\mathrm{Na}-\mathrm{Sn}$ insertion and de-insertions, and also the improved conductivity owing to the presence of RGO. Shen and coworkers reported a novel synergistic $\mathrm{Ni}_{3} \mathrm{~S}_{2}-\mathrm{MoS}_{2}$ core-shell nanofiber superstructure on three dimensional nickel/graphene foam using a one- step polyvinylpyrrolidone-assisted hydrothermal reaction. ${ }^{[184]}$ The as-fabricated hierarchical nanofibers can provide homogeneous atomic heterointerface with porous hierarchical structure, resulting in a high specific capacity (568 mAh g $\mathrm{m}^{-1}$ at $\left.0.2 \mathrm{~A} \mathrm{~g}^{-1}\right)$, an excellent rate capability $\left(283 \mathrm{mAh} \mathrm{g}^{-1}\right.$ at $5 \mathrm{~A}$ $\left.\mathrm{g}^{-1}\right)$ as well as a good long-term cycle stability $\left(207 \mathrm{mAh} \mathrm{g}^{-1}\right.$ is retained after 400 cycles at 5 $\left.\mathrm{A}^{-1}\right)$, as an anode electrode for SIBs.

Owing to sodium's higher mass/atomic radius and more positive redox potential, SIBs show a lower energy density than LIBs. In particular, for the anodes of SIBs, the main issues include 


\section{WILEY-VCH}

large polarization and rapid capacity fading. Coulombic efficiency of each cycle still needs to be improved, probably due to the insufficient passivation in aprotic polar solvents when compared with LIBs. Moreover, SIBs still suffer from safety hazard because of the usage of organic electrolytes. Instead, using solid state electrolytes is expected to address the problem.

\section{Insert Table 3 here}

\subsection{Other types of batteries}

Besides for LIBs and SIBs, GAs also hold potential applications in other kinds of batteries, such as Li-S, ${ }^{[189-192]} \mathrm{Mg},{ }^{[193]}$ zinc-air/nickel, ${ }^{[194]}$ Li-air batteries, ${ }^{[195,196]}$ etc. For a typical Li-S battery, it consists of a lithium anode, a sulfur cathode, and an electrolyte in between. During discharging, lithium is oxidized at the anode yielding lithium ions and electrons, and sulphur is reduced to lithium sulphide at the cathode. Backward reactions happen during charging. ${ }^{[197]}$ Nazar and co-workers demonstrated a metallic $\mathrm{Co}_{9} \mathrm{~S}_{8}$ material with an interconnected graphene-like nano-architecture which exhibits both metallic conductivity and hierarchical porosity, and the sheets were used as a cathode for Li-S batteries. ${ }^{[189]}$ High discharge capacities of $1130,890,895$, and $863 \mathrm{mAh} \mathrm{g}^{-1}$ were obtained at $\mathrm{C} / 20, \mathrm{C} / 2,1 \mathrm{C}$ and $2 \mathrm{C}$ rates, respectively. An ultralow capacity-fading rate of $0.045 \%$ per cycle over 1500 cycles was achieved. Sheets of oxygenated carbon nitrides ${ }^{[190]}$ and MXenes ${ }^{[191]}$ were also employed as electrodes in Li-S batteries, and both showed high electrochemical performance. Lee et al. reported $\mathrm{NiO} / \mathrm{Ni}(\mathrm{OH})_{2}$ nanoflakes as the active electrode material for a hybrid zinc-air/nickel battery. ${ }^{[194]}$ The hybrid battery shows a remarkably high power density (volumetric, $14000 \mathrm{~W}$ $\mathrm{L}^{-1}$; gravimetric, $2700 \mathrm{~W} \mathrm{~kg}^{-1}$ ), an energy density of $980 \mathrm{Wh} \mathrm{kg}^{-1}$, and an excellent charge rate capability up to 10 times faster than the rate of discharge without any capacity and voltage degradations. Li-air batteries are also interesting energy storage systems due to their high specific energy, based on oxidation of lithium at the anode and reduction of oxygen at the cathode to induce a current flow. Salehi-Khojin and co-workers presented a cathode material using $\mathrm{MoS}_{2}$ sheets combined with an ionic liquid, which was employed as an 


\section{WILEY-VCH}

effective co-catalyst for discharge and charge in a $\mathrm{Li}^{-} \mathrm{O}_{2}$ battery ${ }^{[195]} \mathrm{CV}$ measurements show excellent catalytic performance for both oxygen reduction and evolution reactions compared to $\mathrm{Au}$ and $\mathrm{Pt}$ catalysts. The co-catalyst also performs a high round-trip efficiency $(\sim 85 \%)$ for the first cycle, which drops slightly to $\sim 80 \%$ after 50 cycles. All these studies open the door for further development of new type of advanced battery systems with high power and energy density.

\section{Summary and Outlooks}

The continuously growing interest in graphene related materials is reminiscent of the first decade of gold-rush on graphene. The broadest diversity of available GAs featuring welldistinct physical and chemical properties offers potential for breakthroughs in energy applications, and in particular for the development of high performance energy storage devices. In this review, we have summarized the recent developments on the use of GAs as electrode materials for electrochemical energy storage devices, such as supercapacitors and batteries. Although the progress in this highly dynamic field is quite impressive, the use of GAs in energy storage devices is still in its infancy. Presently their performance in energy storage devices is still low and needs to be drastically improved to target the goals of scalable applications and a promising market foreground. In particular, their inferior high rate performance and cycling stability hinder the implementation in real devices. Developing electrolyte/electrode systems that are efficient, stable, and cost-effective is still highly demanded.

Currently, either two- or three-electrode configurations are used to measure the performance of supercapacitors. However, it is known that, under lower current conditions, three-electrode configurations exhibit higher values of capacitance than two-electrode based architectures. ${ }^{[3,}$ ${ }^{198]}$ In order to properly and fairly compare the results within literature, supercapacitors 


\section{WILEY-VCH}

integrating GAs should be characterized by using and comparing the results obtained with

both two- and three-electrode configurations. ${ }^{[199]}$ In order to further improve the performance of supercapacitors, it is essential to gain a better understanding on the dominant factors contributing to the capacitance. As for batteries, tremendous research efforts are still required on the design and study of new GAs and their hybrids as components for electrodes featuring a higher storage capacity, an improved columbic efficiency and a longer cycling life. For LIBs, there is still debate regarding to the actual lithiation reaction sequence during charging/discharging processes. For SIBs, low capacity and poor rate capability of existing anodes are the bottlenecks for future developments. Also, when one wants to compare the capacity from one material to another, a particular attention should be paid to the potential window, electrolytes, and composition of electrodes, charge/discharge efficiency as well as volumetric and areal capacities, all of which are largely overlooked/neglected. Recently, some efforts have already been made to design hybrid energy storage devices such as lithium/sodium-ion hybrid capacitors, ${ }^{[200,201]}$ which are expected to bridge the gap between LIBs and supercapacitors, possessing both high energy and power density.

The practical application of energy storage devices will depend critically on the preparation of novel functional layered materials with the advantages of low cost, high efficiency, large scale, and outstanding properties. Among the various methods proposed, top-down liquid-phase exfoliation and bottom-up wet chemical synthesis in liquid mediums are the most promising approaches to meet these requirements. Despite numerous efforts on the synthesis of a wide range of GAs, there is still a lack of reliable mass production methods to control their thicknesses (e.g., with a high percentage of single-layer sheets or well-defined numbers of layers on a large scale) and sizes to keep the morphology more homogeneously. Thus, new preparation strategies are highly and urgently demanded to produce high quality other 2D materials in a controlled way. The rational design of unique nanostructures holds the potential to solve the issues encountered during the electrochemical processes, thus may dramatically 


\section{WILEY-VCH}

increase the capacity and cycle life of energy storage devices. Increase of the specific surface area and optimization of the pore sizes and pore size distribution of GAs can be achieved by developing hierarchically porous nanostructures. The interfacial interactions between GAs and conductive fillers should be optimized by taking full advantage of the synergistic effects between the individual components, in order to minimize volume changes during charging/discharging. An emerging direction for GAs relies on designing new nanostructures, such as sandwiched multilayers and 3D hybrid structures with tuneable compositions/interlayer distances, for energy-related applications.

Although the excellent electrochemical properties of GAs have been revealed and studied, much needs to be done on the exploitation of these emerging properties for harnessing the device performance. Towards this end, a great effort should be devoted to unravelling the structure-electrochemical property relationships, which will be key for the design of novel electrode materials with superior performance. Major step forward in layered materials application in energy storage can be foreseen only when a fundamental understanding on the structures of electrodes, the electrode/electrolyte interfaces, and charge-storage mechanisms is attained, requiring both experimental and theoretical contributions. ${ }^{[202]}$ Furthermore, the influence of defects on the electrochemical properties of layered materials needs to be systematically studied. Increasing the operating voltage is a useful way to improve the overall electrochemical performance (e.g., gravimetric energy density and power density) by choosing a suitable electrolyte with a high operating voltage window (organic electrolytes or ionic liquids).

When dealing with the design of graphene related materials for energy storage, it is key to find solutions that combine reasonable costs with acceptable performance. In other words, specific capacity, energy density, power density, life, cost, and safety, all need to be taken into serious consideration and should be well-balanced. Technically, light-weight, flexible energy storage systems that combine both outstanding electrochemical and mechanical (e.g., bending/ 


\section{WILEY-VCH}

stretching) performance will boost the development and commercialization of next generation flexible electronics. From the practical point of view, there is still a large technical gap existing between laboratory research and industrial manufacturing. Therefore, a closer collaboration between the communities of academy and industry is needed to solve the encountered issues jointly, such as a low packing density and a strong tendency of aggregation during processing for GAs, and accommodation of large volume changes during charge/discharge cycles. Despite these big challenges to be tacked, the future of GAs in energy storage devices is still bright. With the rapid progress of intense research on these unique materials from both academy and industry, it is reasonable to expect that large-scale, low-cost preparation of nanostructured GAs with ad-hoc electrochemical performance could be realized for practical applications in the near future.

\section{Acknowledgements}

This work was supported by the European Commission through the Graphene Flagship (GA604391), the FP7-NMP-2012-SMALL-6 "SACS" project (GA-310651), as well as the Agence Nationale de la Recherche through the LabEx CSC (ANR-10-LABX-0026_CSC), the International Center for Frontier Research in Chemistry (icFRC).

Received: ((will be filled in by the editorial staff))

Revised: ((will be filled in by the editorial staff)) Published online: ((will be filled in by the editorial staff)) 


\section{WILEY-VCH}

[1] Y. Gogotsi, P. Simon, Science 2011, 334, 917.

[2] P. Simon, Y. Gogotsi, Nat. Mater. 2008, 7, 845.

[3] M. D. Stoller, R. S. Ruoff, Energy Environ. Sci. 2010, 3, 1294.

[4] F. Bonaccorso, L. Colombo, G. Yu, M. Stoller, V. Tozzini, A. C. Ferrari, R. S. Ruoff, V. Pellegrini, Science 2015, 347, 1246501.

[5] D. Larcher, J. M. Tarascon, Nat. Chem. 2015, 7, 19.

[6] Y. Huang, J. Liang, Y. Chen, Small 2012, 8, 1805.

[7] A. C. Ferrari, F. Bonaccorso, V. Fal'ko, K. S. Novoselov, S. Roche, P. Boggild, S.

Borini, F. H. Koppens, V. Palermo, N. Pugno, J. A. Garrido, R. Sordan, A. Bianco, L.

Ballerini, M. Prato, E. Lidorikis, J. Kivioja, C. Marinelli, T. Ryhanen, A. Morpurgo, J. N.

Coleman, V. Nicolosi, L. Colombo, A. Fert, M. Garcia-Hernandez, A. Bachtold, G. F.

Schneider, F. Guinea, C. Dekker, M. Barbone, Z. Sun, C. Galiotis, A. N. Grigorenko, G.

Konstantatos, A. Kis, M. Katsnelson, L. Vandersypen, A. Loiseau, V. Morandi, D. Neumaier, E. Treossi, V. Pellegrini, M. Polini, A. Tredicucci, G. M. Williams, B. H. Hong, J. H. Ahn, J. M. Kim, H. Zirath, B. J. van Wees, H. van der Zant, L. Occhipinti, A. Di Matteo, I. A.

Kinloch, T. Seyller, E. Quesnel, X. Feng, K. Teo, N. Rupesinghe, P. Hakonen, S. R. Neil, Q. Tannock, T. Lofwander, J. Kinaret, Nanoscale 2015, 7, 4598.

[8] X. Y. Zhang, L. L. Hou, P. Samorì, Nat. Commun. 2016, 7, 11128.

[9] W. Feng, W. Luo, Y. Feng, Nanoscale 2012, 4, 6118.

[10] X. Wan, Y. Huang, Y. Chen, Acc. Chem. Res. 2012, 45, 598.

[11] C. N. R. Rao, H. S. S. Ramakrishna Matte, U. Maitra, Angew. Chem. Int. Ed. 2013, 52, 13162.

[12] Y. Sun, S. Gao, F. Lei, C. Xiao, Y. Xie, Acc. Chem. Res. 2015, 48, 3.

[13] S. L. Li, K. Tsukagoshi, E. Orgiu, P. Samorì, Chem. Soc. Rev. 2016, 45, 118.

[14] X. Y. Zhang, E. H. Huisman, M. Gurram, W. R. Browne, B. J. van Wees, B. L.

Feringa, Small 2014, 10, 1735.

[15] H. Wang, H. Feng, J. Li, Small 2014, 10, 2165.

[16] H. Li, Y. Shi, M.-H. Chiu, L.-J. Li, Nano Energy 2015, 18, 293.

[17] R. Mas-Balleste, C. Gomez-Navarro, J. Gomez-Herrero, F. Zamora, Nanoscale 2011, 3,20 .

[18] K. F. Mak, C. Lee, J. Hone, J. Shan, T. F. Heinz, Phys. Rev. Lett. 2010, 105, 136805. [19] Z. Yu, Z.-Y. Ong, Y. Pan, Y. Cui, R. Xin, Y. Shi, B. Wang, Y. Wu, T. Chen, Y.-W. Zhang, G. Zhang, X. Wang, Adv. Mater. 2016, 28, 547.

[20] Y.-K. Hsu, Y.-C. Chen, Y.-G. Lin, L.-C. Chen, K.-H. Chen, J. Mater. Chem. 2012, 22, 2733.

[21] H. Liu, A. T. Neal, Z. Zhu, Z. Luo, X. Xu, D. Tomanek, P. D. Ye, ACS Nano 2014, 8, 4033.

[22] L. Li, Y. Yu, G. J. Ye, Q. Ge, X. Ou, H. Wu, D. Feng, X. H. Chen, Y. Zhang, Nat. Nanotechnol. 2014, 9, 372.

[23] J.-C. Lei, X. Zhang, Z. Zhou, Front. Phys. 2015, 10, 276.

[24] A. Miranda, J. Halim, M. W. Barsoum, A. Lorke, Appl. Phys. Lett. 2016, 108, 033102.

[25] L. Matthes, O. Pulci, F. Bechstedt, J. Phys.: Condens. Matter 2013, 25, 395305.

[26] L. Tao, E. Cinquanta, D. Chiappe, C. Grazianetti, M. Fanciulli, M. Dubey, A. Molle, D. Akinwande, Nat. Nanotechnol. 2015, 10, 227.

[27] Y. Peng, Z. Meng, C. Zhong, J. Lu, W. Yu, Y. Jia, Y. Qian, Chem. Lett. 2001, 30, 772.

[28] Z. Jia, J. Wang, Y. Wang, B. Li, B. Wang, T. Qi, X. Wang, J. Mater. Sci. Technol.

2016, 32, 147.

[29] J. Sun, H. W. Lee, M. Pasta, H. Yuan, G. Zheng, Y. Sun, Y. Li, Y. Cui, Nat.

Nanotechnol. 2015, 10, 980.

[30] M. Naguib, J. Come, B. Dyatkin, V. Presser, P.-L. Taberna, P. Simon, M. W. Barsoum, Y. Gogotsi, Electrochem. Commun. 2012, 16, 61. 


\section{WILEY-VCH}

[31] X. Chia, A. Y. S. Eng, A. Ambrosi, S. M. Tan, M. Pumera, Chem. Rev. 2015, 115, 11941.

[32] M. Chhowalla, H. S. Shin, G. Eda, L. J. Li, K. P. Loh, H. Zhang, Nat. Chem. 2013, 5, 263.

[33] R. Lv, J. A. Robinson, R. E. Schaak, D. Sun, Y. Sun, T. E. Mallouk, M. Terrones, Acc. Chem. Res. 2015, 48, 56.

[34] V. Nicolosi, M. Chhowalla, M. G. Kanatzidis, M. S. Strano, J. N. Coleman, Science 2013, 340, 1226419.

[35] Q. H. Wang, K. Kalantar-Zadeh, A. Kis, J. N. Coleman, M. S. Strano, Nat. Nanotechnol. 2012, 7, 699.

[36] M. Xu, T. Liang, M. Shi, H. Chen, Chem. Rev. 2013, 113, 3766.

[37] H. Zhang, ACS Nano 2015, 9, 9451.

[38] G. Eda, H. Yamaguchi, D. Voiry, T. Fujita, M. Chen, M. Chhowalla, Nano Lett. 2011, 11,5111 .

[39] J. N. Coleman, M. Lotya, A. O'Neill, S. D. Bergin, P. J. King, U. Khan, K. Young, A. Gaucher, S. De, R. J. Smith, I. V. Shvets, S. K. Arora, G. Stanton, H. Y. Kim, K. Lee, G. T. Kim, G. S. Duesberg, T. Hallam, J. J. Boland, J. J. Wang, J. F. Donegan, J. C. Grunlan, G. Moriarty, A. Shmeliov, R. J. Nicholls, J. M. Perkins, E. M. Grieveson, K. Theuwissen, D. W. McComb, P. D. Nellist, V. Nicolosi, Science 2011, 331, 568.

[40] H. Li, J. Wu, Z. Yin, H. Zhang, Acc. Chem. Res. 2014, 47, 1067.

[41] M. Yi, Z. Shen, J. Mater. Chem. A 2015, 3, 11700.

[42] J. Cai, P. Ruffieux, R. Jaafar, M. Bieri, T. Braun, S. Blankenburg, M. Muoth, A. P. Seitsonen, M. Saleh, X. Feng, K. Müllen, R. Fasel, Nature 2010, 466, 470.

[43] D. Lembke, S. Bertolazzi, A. Kis, Acc. Chem. Res. 2015, 48, 100.

[44] X. Y. Zhang, A. C. Coleman, N. Katsonis, W. R. Browne, B. J. van Wees, B. L.

Feringa, Chem. Commun. 2010, 46, 7539.

[45] X. Y. Zhang, L. L. Hou, A. Cnossen, A. C. Coleman, O. Ivashenko, P. Rudolf, B. J. van Wees, W. R. Browne, B. L. Feringa, Chem. Eur. J. 2011, 17, 8957.

[46] A. Ciesieslki, P. Samorì, Adv. Mater. 2016, DOI: 10.1002/adma.201505371.

[47] X. Y. Zhang, W. R. Browne, B. L. Feringa, RSC Adv. 2012, 2, 12173.

[48] K. Parvez, Z. S. Wu, R. Li, X. Liu, R. Graf, X. Feng, K. Müllen, J. Am. Chem. Soc. 2014, 136, 6083.

[49] N. Liu, P. Kim, J. H. Kim, J. H. Ye, S. Kim, C. J. Lee, ACS Nano 2014, 8, 6902.

[50] Z. Zeng, T. Sun, J. Zhu, X. Huang, Z. Yin, G. Lu, Z. Fan, Q. Yan, H. H. Hng, H.

Zhang, Angew. Chem. Int. Ed. 2012, 51, 9052.

[51] S. Yang, M. R. Lohe, K. Müllen, X. Feng, Adv. Mater. 2016, DOI:

10.1002/adma.201505326.

[52] Z. Y. Xia, S. Pezzini, E. Treossi, G. Giambastiani, F. Corticelli, V. Morandi, A.

Zanelli, V. Bellani, V. Palermo, Adv. Funct. Mater. 2013, 23, 4684.

[53] X. Fan, P. Xu, D. Zhou, Y. Sun, Y. C. Li, M. A. Nguyen, M. Terrones, T. E. Mallouk, Nano Lett. 2015, 15, 5956.

[54] J. C. Shaw, H. Zhou, Y. Chen, N. O. Weiss, Y. Liu, Y. Huang, X. Duan, Nano Res. 2015, 7, 511 .

[55] D. Kong, H. Wang, J. J. Cha, M. Pasta, K. J. Koski, J. Yao, Y. Cui, Nano Lett. 2013, $13,1341$.

[56] Y. Zhan, Z. Liu, S. Najmaei, P. M. Ajayan, J. Lou, Small 2012, 8, 966.

[57] Z. Sun, T. Liao, Y. Dou, S. M. Hwang, M. S. Park, L. Jiang, J. H. Kim, S. X. Dou, Nat. Commun. 2014, 5, 3813.

[58] L. L. Zhang, X. S. Zhao, Chem. Soc. Rev. 2009, 38, 2520.

[59] G. Wang, L. Zhang, J. Zhang, Chem. Soc. Rev. 2012, 41, 797.

[60] L. Dai, D. W. Chang, J. B. Baek, W. Lu, Small 2012, 8, 1130. 


\section{WILEY-VCH}

[61] Y. Zhai, Y. Dou, D. Zhao, P. F. Fulvio, R. T. Mayes, S. Dai, Adv. Mater. 2011, 23, 4828.

[62] K. Hong, M. Cho, S. O. Kim, ACS Appl. Mater. Interfaces 2015, 7, 1899.

[63] D. Feng, Y. Lv, Z. Wu, Y. Dou, L. Han, Z. Sun, Y. Xia, G. Zheng, D. Zhao, J. Am. Chem. Soc. 2011, 133, 15148.

[64] H. He, L. Shi, Y. Fang, X. Li, Q. Song, L. Zhi, Small 2014, 10, 4671.

[65] D. N. Futaba, K. Hata, T. Yamada, T. Hiraoka, Y. Hayamizu, Y. Kakudate, O.

Tanaike, H. Hatori, M. Yumura, S. Iijima, Nat. Mater. 2006, 5, 987.

[66] C. Liu, Z. Yu, D. Neff, A. Zhamu, B. Z. Jang, Nano Lett. 2010, 10, 4863.

[67] J. Chmiola, C. Largeot, P. L. Taberna, P. Simon, Y. Gogotsi, Science 2010, 328, 480.

[68] E. G. da Silveira Firmiano, A. C. Rabelo, C. J. Dalmaschio, A. N. Pinheiro, E. C.

Pereira, W. H. Schreiner, E. R. Leite, Adv. Energy Mater. 2014, 4, 1301380.

[69] H. Ji, C. Liu, T. Wang, J. Chen, Z. Mao, J. Zhao, W. Hou, G. Yang, Small 2015, 11, 6480.

[70] M. Acerce, D. Voiry, M. Chhowalla, Nat. Nanotechnol. 2015, 10, 313.

[71] M. A. Bissett, I. A. Kinloch, R. A. W. Dryfe, ACS Appl. Mater. Interfaces 2015, 7, 17388.

[72] Y. Yang, H. Fei, G. Ruan, C. Xiang, J. M. Tour, Adv. Mater. 2014, 26, 8163.

[73] J. M. Soon, K. P. Loh, Electrochem. Solid-State Lett. 2007, 10, A250.

[74] J. Feng, X. Sun, C. Wu, L. Peng, C. Lin, S. Hu, J. Yang, Y. Xie, J. Am. Chem. Soc. 2011, 133, 17832.

[75] L. Pan, G. Yu, D. Zhai, H. R. Lee, W. Zhao, N. Liu, H. Wang, B. C. Tee, Y. Shi, Y.

Cui, Z. Bao, Proc. Natl. Acad. Sci. 2012, 109, 9287.

[76] Q. Yang, Z. Lu, X. Sun, J. Liu, Sci. Rep. 2013, 3, 3537.

[77] Y. Zhang, Y. Liu, J. Chen, Q. Guo, T. Wang, H. Pang, Sci. Rep. 2014, 4, 5687.

[78] S. Gao, Y. Sun, F. Lei, L. Liang, J. Liu, W. Bi, B. Pan, Y. Xie, Angew. Chem. Int. Ed. 2014, 53, 12789.

[79] H. Li, Y. Gao, C. Wang, G. Yang, Adv. Energy Mater. 2015, 5, 1401767.

[80] M. Ghidiu, M. R. Lukatskaya, M.-Q. Zhao, Y. Gogotsi, M. W. Barsoum, Nature 2014, 516,78 .

[81] M. R. Lukatskaya, S.-M. Bak, X. Yu, X.-Q. Yang, M. W. Barsoum, Y. Gogotsi, Adv. Energy Mater. 2015, 5, 1500589.

[82] M. Boota, B. Anasori, C. Voigt, M. Q. Zhao, M. W. Barsoum, Y. Gogotsi, Adv. Mater. 2016, 28, 1517.

[83] Z. Ling, C. E. Ren, M.-Q. Zhao, J. Yang, J. M. Giammarco, J. Qiu, M. W. Barsoum, Y. Gogotsi, Proc. Natl. Acad. Sci. 2014, 111, 16676.

[84] J. Yan, Z. Fan, W. Sun, G. Ning, T. Wei, Q. Zhang, R. Zhang, L. Zhi, F. Wei, Adv. Funct. Mater. 2012, 22, 2632.

[85] J. Chang, M. Jin, F. Yao, T. H. Kim, V. T. Le, H. Yue, F. Gunes, B. Li, A. Ghosh, S. Xie, Y. H. Lee, Adv. Funct. Mater. 2013, 23, 5074.

[86] G. Sun, J. Liu, X. Zhang, X. Wang, H. Li, Y. Yu, W. Huang, H. Zhang, P. Chen, Angew. Chem. Int. Ed. 2014, 53, 12576.

[87] F. Grote, Z. Y. Yu, J. L. Wang, S. H. Yu, Y. Lei, Small 2015, 11, 4666.

[88] M. Q. Zhao, C. E. Ren, Z. Ling, M. R. Lukatskaya, C. Zhang, K. L. Van Aken, M. W. Barsoum, Y. Gogotsi, Adv. Mater. 2015, 27, 339.

[89] T. Zhu, H. B. Wu, Y. Wang, R. Xu, X. W. Lou, Adv. Energy Mater. 2012, 2, 1497.

[90] J. Zhao, J. Chen, S. Xu, M. Shao, Q. Zhang, F. Wei, J. Ma, M. Wei, D. G. Evans, X. Duan, Adv. Funct. Mater. 2014, 24, 2938.

[91] N. Yu, H. Yin, W. Zhang, Y. Liu, Z. Tang, M.-Q. Zhu, Adv. Energy Mater. 2016, 6, 1501458. 


\section{WILEY-VCH}

[92] J. Zhang, J. Fu, J. Zhang, H. Ma, Y. He, F. Li, E. Xie, D. Xue, H. Zhang, Y. Peng, Small 2014, 10, 2618.

[93] P. Tang, L. Han, L. Zhang, S. Wang, W. Feng, G. Xu, L. Zhang, ChemElectroChem $\mathbf{2 0 1 5}, 2,949$.

[94] H. Tang, J. Wang, H. Yin, H. Zhao, D. Wang, Z. Tang, Adv. Mater. 2015, 27, 1117.

[95] J. Zhu, W. Sun, D. Yang, Y. Zhang, H. H. Hoon, H. Zhang, Q. Yan, Small 2015, 11, 4123.

[96] J. Zhao, S. Xu, K. Tschulik, R. G. Compton, M. Wei, D. O'Hare, D. G. Evans, X. Duan, Adv. Funct. Mater. 2015, 25, 2745.

[97] S. Peng, L. Li, H. B. Wu, S. Madhavi, X. W. Lou, Adv. Energy Mater. 2015, 5, 1401172.

[98] J. Ji, L. L. Zhang, H. Ji, Y. Li, X. Zhao, X. Bai, X. Fan, F. Zhang, R. S. Ruoff, ACS Nano 2013, 7, 6237.

[99] J. Chen, J. Xu, S. Zhou, N. Zhao, C.-P. Wong, Nano Energy 2016, 21, 145.

[100] K. M. Hercule, Q. Wei, O. K. Asare, L. Qu, A. M. Khan, M. Yan, C. Du, W. Chen, L. Mai, Adv. Energy Mater. 2015, 5, 1500060.

[101] J.-X. Feng, S.-H. Ye, A.-L. Wang, X.-F. Lu, Y.-X. Tong, G.-R. Li, Adv. Funct. Mater. 2014, 24, 7093.

[102] X. Wang, C. Yan, A. Sumboja, J. Yan, P. S. Lee, Adv. Energy Mater. 2014, 4, 1301240.

[103] Y. Tang, Y. Zhang, W. Li, B. Ma, X. Chen, Chem. Soc. Rev. 2015, 44, 5926.

[104] J. B. Goodenough, Y. Kim, Chem. Mater. 2010, 22, 587.

[105] G. Wang, X. Shen, J. Yao, J. Park, Carbon 2009, 47, 2049.

[106] M. Liang, L. Zhi, J. Mater. Chem. 2009, 19, 5871.

[107] Y. J. Lee, Y. Lee, D. Oh, T. Chen, G. Ceder, A. M. Belcher, Nano Lett. 2010, 10, 2433.

[108] P. Poizot, S. Laruelle, S. Grugeon, L. Dupont, J. M. Tarascon, Nature 2000, 407, 496.

[109] M. V. Reddy, G. V. Subba Rao, B. V. Chowdari, Chem. Rev. 2013, 113, 5364.

[110] K. Cao, L. Jiao, H. Liu, Y. Liu, Y. Wang, Z. Guo, H. Yuan, Adv. Energy Mater. 2015, 5,1401421 .

[111] J. Zhu, Z. Yin, D. Yang, T. Sun, H. Yu, H. E. Hoster, H. H. Hng, H. Zhang, Q. Yan, Energy Environ. Sci. 2013, 6, 987.

[112] Y. Li, J. Yao, E. Uchaker, J. Yang, Y. Huang, M. Zhang, G. Cao, Adv. Energy Mater. 2013, 3, 1171.

[113] M. Liu, C. Yan, Y. Zhang, Sci. Rep. 2015, 5, 8326.

[114] J. S. Chen, Y. L. Tan, C. M. Li, Y. L. Cheah, D. Luan, S. Madhavi, F. Y. Boey, L. A. Archer, X. W. Lou, J. Am. Chem. Soc. 2010, 132, 6124.

[115] H. Hu, L. Yu, X. Gao, Z. Lin, X. W. Lou, Energy Environ. Sci. 2015, 8, 1480.

[116] Q. Wu, J. Xu, X. Yang, F. Lu, S. He, J. Yang, H. J. Fan, M. Wu, Adv. Energy Mater.

$\mathbf{2 0 1 5}, 5,1401756$.

[117] G. Yang, H. Cui, G. Yang, C. Wang, ACS Nano 2014, 8, 4474.

[118] D. Rangappa, K. D. Murukanahally, T. Tomai, A. Unemoto, I. Honma, Nano Lett. 2012, 12, 1146.

[119] T. Liu, Y. Feng, Y. Duan, S. Cui, L. Lin, J. Hu, H. Guo, Z. Zhuo, J. Zheng, Y. Lin, W. Yang, K. Amine, F. Pan, Nano Energy 2015, 18, 187.

[120] H. Wang, S. Liu, Y. Ren, W. Wang, A. Tang, Energy Environ. Sci. 2012, 5, 6173.

[121] S. Jin, G. Yang, H. Song, H. Cui, C. Wang, ACS Appl. Mater. Interfaces 2015, 7, 24932.

[122] L. Sun, T. Su, L. Xu, M. Liu, H.-B. Du, Chem. Commun. 2016, 52, 4341.

[123] Y.-S. Hu, R. Demir-Cakan, M.-M. Titirici, J.-O. Müller, R. Schlögl, M. Antonietti, J. Maier, Angew. Chem. Int. Ed. 2008, 47, 1645.

[124] H. Liu, D. Su, R. Zhou, B. Sun, G. Wang, S. Z. Qiao, Adv. Energy Mater. 2012, 2, 970. 


\section{WILEY-VCH}

[125] Y. Chen, B. Song, X. Tang, L. Lu, J. Xue, Small 2014, 10, 1536.

[126] S. Qin, W. Lei, D. Liu, Y. Chen, J. Mater. Chem. A 2016, 4, 1440.

[127] L. Luo, B. Zhao, B. Xiang, C.-M. Wang, ACS Nano 2016, 10, 1249.

[128] Y. Zhang, X. Rui, Y. Tang, Y. Liu, J. Wei, S. Chen, W. R. Leow, W. Li, Y. Liu, J.

Deng, B. Ma, Q. Yan, X. Chen, Adv. Energy Mater. 2016, 1502409.

[129] J. Luo, X. Tao, J. Zhang, Y. Xia, H. Huang, L. Zhang, Y. Gan, C. Liang, W. Zhang, ACS Nano 2016, 10, 2491.

[130] M. Naguib, J. Halim, J. Lu, K. M. Cook, L. Hultman, Y. Gogotsi, M. W. Barsoum, J. Am. Chem. Soc. 2013, 135, 15966.

[131] Y. Dou, J. Xu, B. Ruan, Q. Liu, Y. Pan, Z. Sun, S. X. Dou, Adv. Energy Mater. 2016, 1501835.

[132] V. Etacheri, J. E. Yourey, B. M. Bartlett, ACS Nano 2014, 8, 1491.

[133] C. Chen, X. Hu, Y. Jiang, Z. Yang, P. Hu, Y. Huang, Chem. Eur. J. 2014, 20, 1383.

[134] G. Zhou, D. W. Wang, L. C. Yin, N. Li, F. Li, H. M. Cheng, ACS Nano 2012, 6, 3214.

[135] P. Xiong, L. Peng, D. Chen, Y. Zhao, X. Wang, G. Yu, Nano Energy 2015, 12, 816.

[136] G. Gao, H. B. Wu, B. Dong, S. Ding, X. W. Lou, Adv. Sci. 2015, $2,1400014$.

[137] G. Gao, H. B. Wu, X. W. Lou, Adv. Energy Mater. 2014, 4, 1400422.

[138] S. M. Hao, J. Qu, J. Yang, C. X. Gui, Q. Q. Wang, Q. J. Li, X. Li, Z. Z. Yu, Chem.

Eur. J. 2016, 22, 3397.

[139] C. S. Rout, B. H. Kim, X. Xu, J. Yang, H. Y. Jeong, D. Odkhuu, N. Park, J. Cho, H. S. Shin, J. Am. Chem. Soc. 2013, 135, 8720.

[140] L. Ma, J. Ye, W. Chen, D. Chen, J. Yang Lee, Nano Energy 2014, 10, 144.

[141] G. Huang, T. Chen, W. Chen, Z. Wang, K. Chang, L. Ma, F. Huang, D. Chen, J. Y. Lee, Small 2013, 9, 3693.

[142] R. Wang, C. Xu, J. Sun, Y. Liu, L. Gao, H. Yao, C. Lin, Nano Energy 2014, 8, 183.

[143] X. Cao, Y. Shi, W. Shi, X. Rui, Q. Yan, J. Kong, H. Zhang, Small 2013, 9, 3433.

[144] J. Wang, J. Liu, D. Chao, J. Yan, J. Lin, Z. X. Shen, Adv. Mater. 2014, 26, 7162.

[145] Z. Yu, J. Song, M. L. Gordin, R. Yi, D. Tang, D. Wang, Adv. Sci. 2015, 2, 21400020.

[146] L. Chen, G. Zhou, Z. Liu, X. Ma, J. Chen, Z. Zhang, X. Ma, F. Li, H. M. Cheng, W.

Ren, Adv. Mater. 2016, 28, 510.

[147] G. Huang, H. Liu, S. Wang, X. Yang, B. Liu, H. Chen, M. Xu, J. Mater. Chem. A 2015, 3, 24128.

[148] Z. X. Huang, Y. Wang, J. I. Wong, H. Y. Yang, 2D Mater. 2015, 2, 024010.

[149] Y. Zhang, H. Wang, Z. Luo, H. T. Tan, B. Li, S. Sun, Z. Li, Y. Zong, Z. J. Xu, Y.

Yang, K. A. Khor, Q. Yan, Adv. Energy Mater. 2016, 1600453.

[150] K. Chang, D. Geng, X. Li, J. Yang, Y. Tang, M. Cai, R. Li, X. Sun, Adv. Energy

Mater. 2013, 3, 839.

[151] Y. Tang, D. Wu, Y. Mai, H. Pan, J. Cao, C. Yang, F. Zhang, X. Feng, Nanoscale 2014, $6,14679$.

[152] X. Wang, G. Li, M. H. Seo, F. M. Hassan, M. A. Hoque, Z. Chen, Adv. Energy Mater. 2015, 5, 1501106.

[153] J. Zhu, K. Sakaushi, G. Clavel, M. Shalom, M. Antonietti, T. P. Fellinger, J. Am.

Chem. Soc. 2015, 137, 5480.

[154] Q. Qu, F. Qian, S. Yang, T. Gao, W. Liu, J. Shao, H. Zheng, ACS Appl. Mater.

Interfaces 2016, 8, 1398.

[155] J.-Z. Wang, L. Lu, M. Lotya, J. N. Coleman, S.-L. Chou, H.-K. Liu, A. I. Minett, J.

Chen, Adv. Energy Mater. 2013, 3, 798.

[156] J. Li, Y. Hou, X. Gao, D. Guan, Y. Xie, J. Chen, C. Yuan, Nano Energy 2015, 16, 10.

[157] S. Ding, J. S. Chen, X. W. Lou, Adv. Funct. Mater. 2011, 21, 4120.

[158] O. Mashtalir, M. R. Lukatskaya, M. Q. Zhao, M. W. Barsoum, Y. Gogotsi, Adv. Mater. 2015, 27, 3501 . 


\section{WILEY-VCH}

[159] J. Ni, Y. Zhao, L. Li, L. Mai, Nano Energy 2015, 11, 129.

[160] X. Rui, X. Zhao, Z. Lu, H. Tan, D. Sim, H. H. Hng, R. Yazami, T. M. Lim, Q. Yan, ACS Nano 2013, 7, 5637.

[161] Q. An, F. Xiong, Q. Wei, J. Sheng, L. He, D. Ma, Y. Yao, L. Mai, Adv. Energy Mater. 2015, 5, 1401963.

[162] J. Ryu, D. Hong, S. Choi, S. Park, ACS Nano 2016, 10, 2843.

[163] N. Li, G. Zhou, F. Li, L. Wen, H.-M. Cheng, Adv. Funct. Mater. 2013, 23, 5429.

[164] H. Jiang, D. Ren, H. Wang, Y. Hu, S. Guo, H. Yuan, P. Hu, L. Zhang, C. Li, Adv.

Mater. 2015, 27, 3687.

[165] Y. Liu, M. Zhu, D. Chen, J. Mater. Chem. A 2015, 3, 11857.

[166] Y. Zhang, Y. Wang, J. Yang, W. Shi, H. Yang, W. Huang, X. Dong, 2D Mater. 2016, 3, 024001 .

[167] G. Gao, S. Lu, B. Dong, Z. Zhang, Y. Zheng, S. Ding, J. Mater. Chem. A 2015, 3, 4716.

[168] Z. Wan, J. Shao, J. Yun, H. Zheng, T. Gao, M. Shen, Q. Qu, H. Zheng, Small 2014, 10, 4975.

[169] F. Zhou, S. Xin, H. W. Liang, L. T. Song, S. H. Yu, Angew. Chem. Int. Ed. 2014, 53, 11552.

[170] X. Y. Yu, H. Hu, Y. Wang, H. Chen, X. W. Lou, Angew. Chem. Int. Ed. 2015, 54, 7395.

[171] J. Deng, C. Yan, L. Yang, S. Baunack, S. Oswald, H. Wendrock, Y. Mei, O. G. Schmidt, ACS Nano 2013, 7, 6948.

[172] L. Yang, S. Wang, J. Mao, J. Deng, Q. Gao, Y. Tang, O. G. Schmidt, Adv. Mater. 2013, 25, 1180 .

[173] S. Guo, H. Yu, Z. Jian, P. Liu, Y. Zhu, X. Guo, M. Chen, M. Ishida, H. Zhou, ChemSusChem 2014, 7, 2115.

[174] S. Guo, P. Liu, H. Yu, Y. Zhu, M. Chen, M. Ishida, H. Zhou, Angew. Chem. Int. Ed. 2015, $54,5894$.

[175] W. Sun, X. Rui, D. Yang, Z. Sun, B. Li, W. Zhang, Y. Zong, S. Madhavi, S. Dou, Q. Yan, ACS Nano 2015, 9, 11371.

[176] D. Su, S. Dou, G. Wang, Adv. Energy Mater. 2015, 5, 1401205.

[177] B. Ahmed, D. H. Anjum, M. N. Hedhili, H. N. Alshareef, Small 2015, 11, 4341.

[178] T. Zhou, W. K. Pang, C. Zhang, J. Yang, Z. Chen, H. K. Liu, Z. Guo, ACS Nano 2014, 8,8323 .

[179] B. Qu, C. Ma, G. Ji, C. Xu, J. Xu, Y. S. Meng, T. Wang, J. Y. Lee, Adv. Mater. 2014, 26,3854 .

[180] Y. Zhang, P. Zhu, L. Huang, J. Xie, S. Zhang, G. Cao, X. Zhao, Adv. Funct. Mater. $\mathbf{2 0 1 5}, 25,481$.

[181] S. H. Choi, Y. N. Ko, J.-K. Lee, Y. C. Kang, Adv. Funct. Mater. 2015, 25, 1780.

[182] X. Xie, Z. Ao, D. Su, J. Zhang, G. Wang, Adv. Funct. Mater. 2015, 25, 1393.

[183] L. David, R. Bhandavat, G. Singh, ACS Nano 2014, 8, 1759.

[184] J. Wang, J. Liu, H. Yang, D. Chao, J. Yan, S. V. Savilov, J. Lin, Z. X. Shen, Nano Energy 2016, 20, 1.

[185] J. Wang, C. Luo, T. Gao, A. Langrock, A. C. Mignerey, C. Wang, Small 2015, 11, 473. [186] X. Xie, T. Makaryan, M. Zhao, K. L. Van Aken, Y. Gogotsi, G. Wang, Adv. Energy Mater. 2016, 6, 1502161.

[187] Y. Lu, Q. Zhao, N. Zhang, K. Lei, F. Li, J. Chen, Adv. Funct. Mater. 2016, 26, 911. [188] Z.-T. Shi, W. Kang, J. Xu, Y.-W. Sun, M. Jiang, T.-W. Ng, H.-T. Xue, D. Y. W. Yu, W. Zhang, C.-S. Lee, Nano Energy 2016, 22, 27.

[189] Q. Pang, D. Kundu, L. F. Nazar, Mater. Horiz. 2016, 3, 130. 


\section{WILEY-VCH}

[190] J. Liu, W. Li, L. Duan, X. Li, L. Ji, Z. Geng, K. Huang, L. Lu, L. Zhou, Z. Liu, W. Chen, L. Liu, S. Feng, Y. Zhang, Nano Lett. 2015, 15, 5137.

[191] X. Liang, A. Garsuch, L. F. Nazar, Angew. Chem. Int. Ed. 2015, 54, 3907.

[192] Z. W. Seh, J. H. Yu, W. Li, P.-C. Hsu, H. Wang, Y. Sun, H. Yao, Q. Zhang, Y. Cui, Nat. Commun. 2014, 5, 5017.

[193] Y. Liang, R. Feng, S. Yang, H. Ma, J. Liang, J. Chen, Adv. Mater. 2011, 23, 640.

[194] D. U. Lee, J. Fu, M. G. Park, H. Liu, A. Ghorbani Kashkooli, Z. Chen, Nano Lett. 2016, 16, 1794.

[195] M. Asadi, B. Kumar, C. Liu, P. Phillips, P. Yasaei, A. Behranginia, P. Zapol, R. F. Klie, L. A. Curtiss, A. Salehi-Khojin, ACS Nano 2016, 10, 2167.

[196] P. Zhang, X. Lu, Y. Huang, J. Deng, L. Zhang, F. Ding, Z. Su, G. Wei, O. G. Schmidt, J. Mater. Chem. A 2015, 3, 14562.

[197] A. Manthiram, Y. Fu, S.-H. Chung, C. Zu, Y.-S. Su, Chem. Rev. 2014, 114, 11751.

[198] V. Khomenko, E. Frackowiak, F. Béguin, Electrochim. Acta 2005, 50, 2499.

[199] X. Y. Zhang, A. Ciesielski, F. Richard, P. Chen, E. A. Prasetyanto, L. De Cola, P.

Samori, Small 2016, 12, 1044.

[200] Y. Ma, H. Chang, M. Zhang, Y. Chen, Adv. Mater. 2015, 27, 5296.

[201] X. Wang, S. Kajiyama, H. Iinuma, E. Hosono, S. Oro, I. Moriguchi, M. Okubo, A. Yamada, Nat. Commun. 2015, 6, 6544.

[202] A. C. Forse, C. Merlet, J. M. Griffin, C. P. Grey, J. Am. Chem. Soc. 2016, DOI: $10.1021 /$ jacs.6b02115. 


\section{WILEY-VCH}

\section{Author biographies and photographs}

Dr. Xiaoyan Zhang obtained his $\mathrm{PhD}$ in December 2013, from Stratingh Institute for Chemistry and Zernike Institute for Advanced Materials, University of Groningen, the Netherlands. He is currently a postdoctoral researcher in the group of Professor Paolo Samorì at the Institut de Science et d'Ingénierie Supramoléculaires (ISIS) of the University of Strasbourg, France. His current research interest focuses on preparation, characterization and functionalization of 2D materials for functional nanocomposites and energy-related applications.

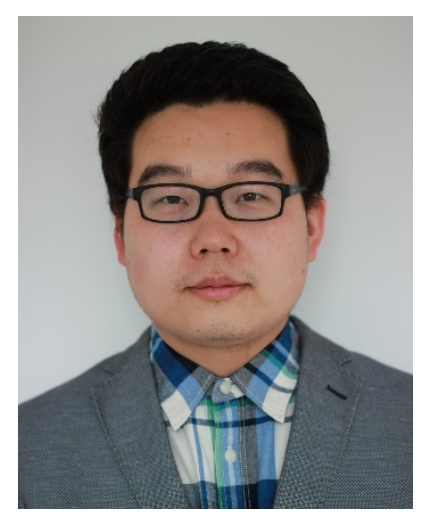

Paolo Samorì is Distinguished Professor and director of the Institut de Science et d'Ingénierie Supramoléculaires (ISIS) of the Universite de Strasbourg (UdS). He is also Fellow of the Royal Society of Chemistry (FRSC), fellow of the European Academy of Sciences (EURASC), member of the Academia Europaea (MAE) and junior member of the Institut Universitaire de France (IUF). His research interests include layered materials, organic semiconductors, hierarchical self-assembly of hybrid architectures, supramolecular electronics, and the fabrication of organic- and graphene-based nanodevices. His work was awarded various prizes, including the Young Scientist Awards at E-MRS (1998) and MRS (2000), the IUPAC Prize for Young Chemists (2001), the "Vincenzo Caglioti" Award (2006) granted by the Accademia Nazionale dei Lincei (Italy), the ERC Starting Grant (2010) and the CNRS Silver Medal (2012).

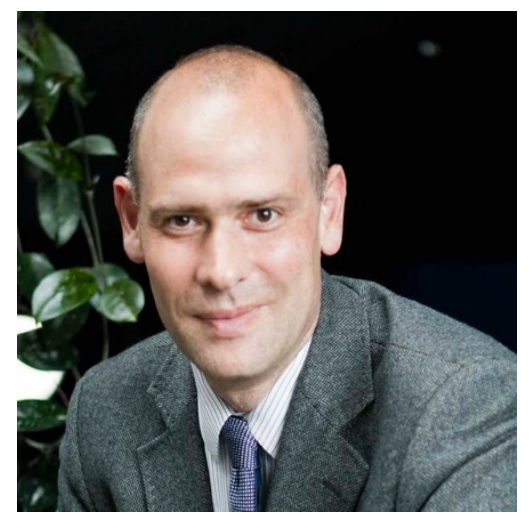




\section{WILEY-VCH}

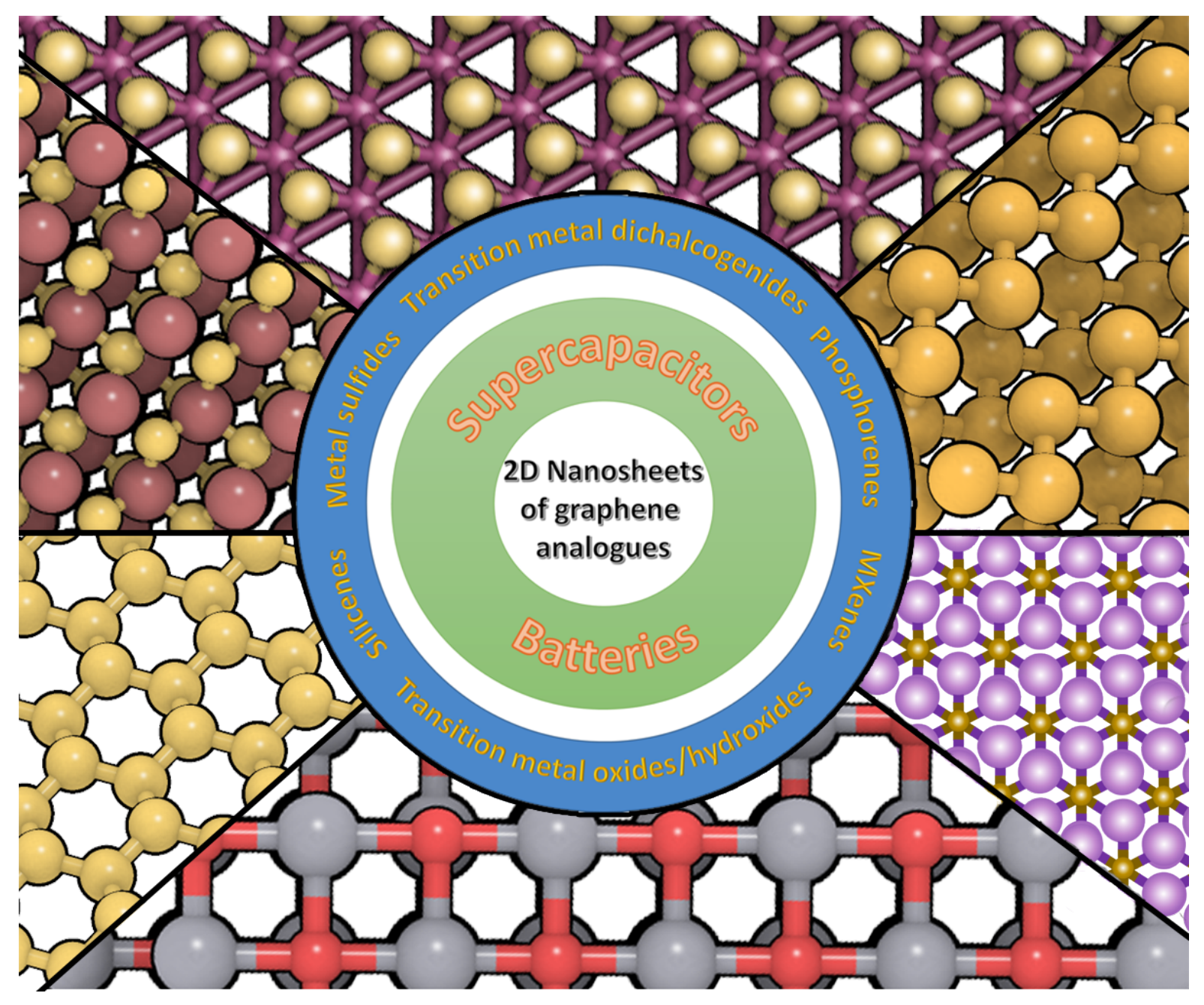

Figure 1. Typical 2D graphene analogues for energy storage and their structures. 


\section{WILEY-VCH}
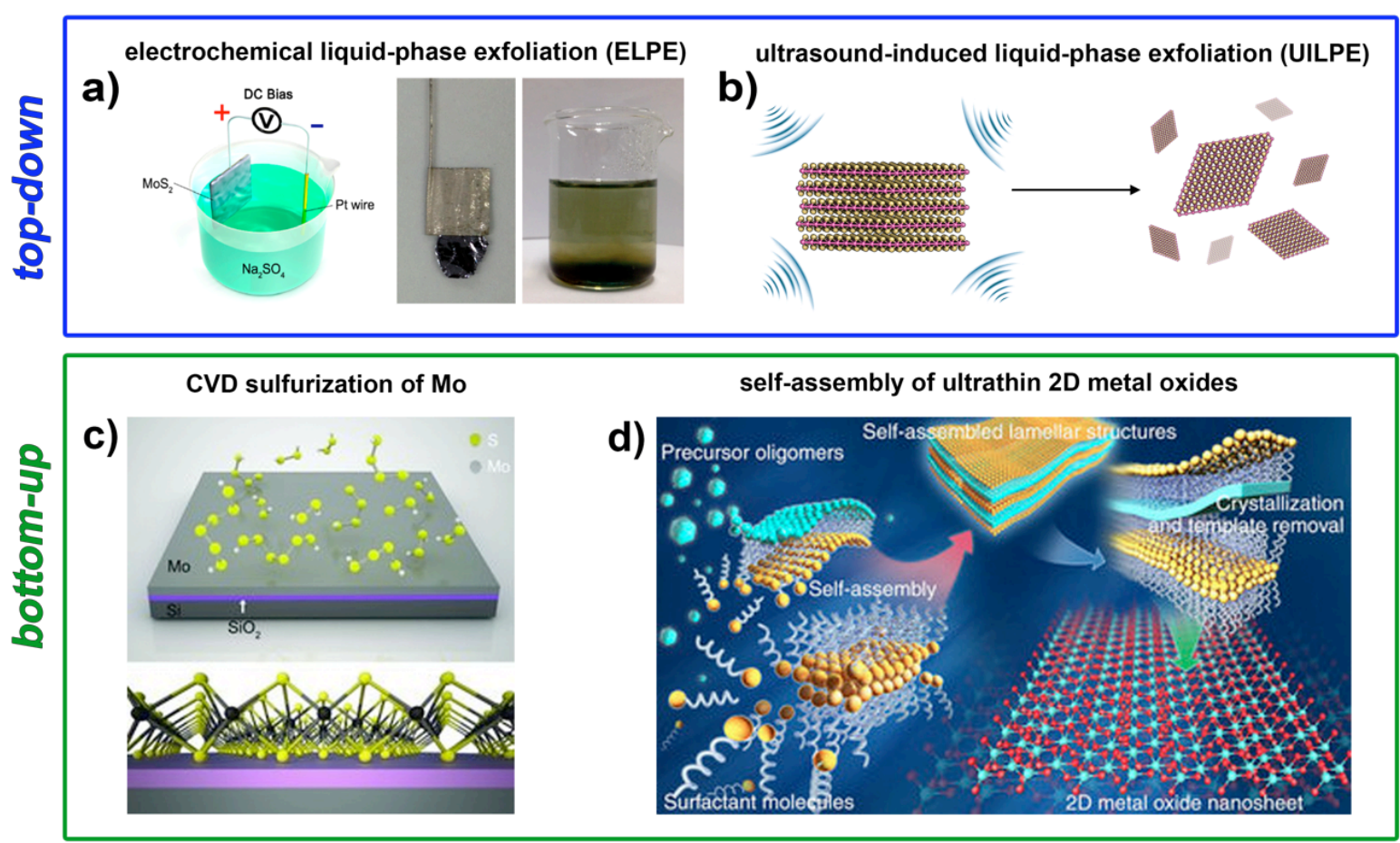

Figure 2. Schematic representation of top-down and bottom-up production methods of 2D materials. a) Schematic illustration of experimental setup for electrochemical liquid-phase exfoliation (ELPE) of bulk $\mathrm{MoS}_{2}$ crystal (left); Photograph of a bulk $\mathrm{MoS}_{2}$ crystal held by a Pt clamp before exfoliation (center); Exfoliated $\mathrm{MoS}_{2}$ flakes suspended in a $\mathrm{Na}_{2} \mathrm{SO}_{4}$ electrolyte (right). Reproduced with permission from reference 49 (Copyright 2014 American Chemical Society). b) Scheme of ultrasound-induced liquid-phase exfoliation (UILPE) of $\mathrm{MoS}_{2}$ crystal into individual sheets. c) CVD based process relying on the introduction of sulphur atoms on the Mo thin film that was pre-deposited on the $\mathrm{SiO}_{2}$ substrate. Reproduced with permission from reference 56 (Copyright 2012 Wiley). d) Schematic shows the concept of molecular assembly of ultrathin 2D metal oxide sheets from liquid solutions, where metal oxide precursor oligomers are self-assembled into 2D metal oxide sheets with atomic thickness. Reproduced with permission from reference 57 (Copyright 2014 Nature Publishing Group). 


\section{WILEY-VCH}

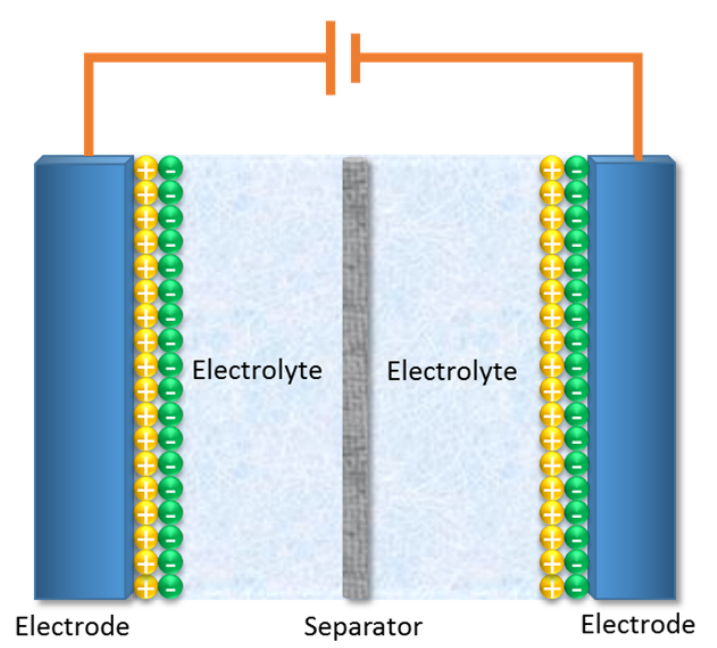

Figure 3. Electrical double-layer capacitors (EDLCs) during charging. 


\section{WILEY-VCH}

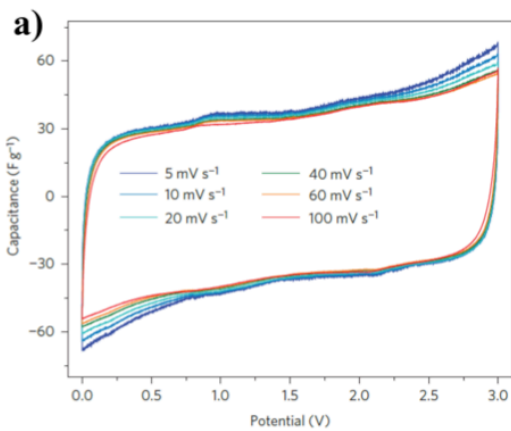

d)

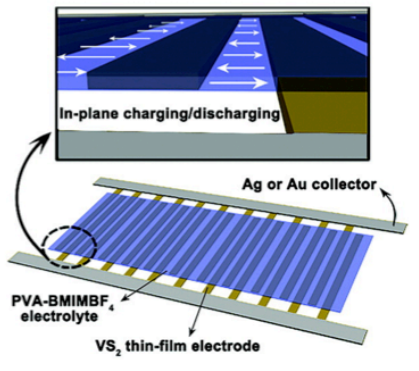

b)
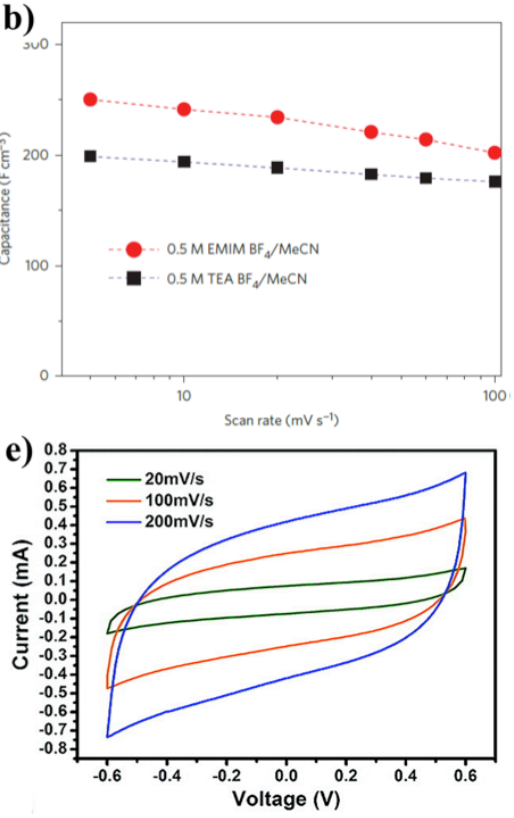
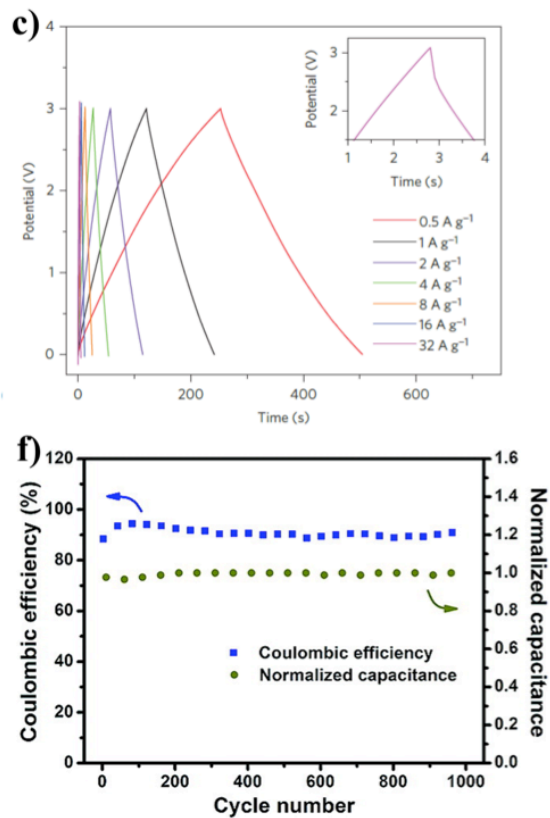

Figure 4. Electrochemical characterization of metallic $\mathrm{MoS}_{2}$ sheets for supercapacitors: a) $\mathrm{CV}$ curves in $1 \mathrm{M}$ TEA $\mathrm{BF}_{4} / \mathrm{MeCN}$. b) Capacitance versus scan rate in TEA $\mathrm{BF}_{4} / \mathrm{MeCN}$ and EMIM $\mathrm{BF}_{4} / \mathrm{MeCN}$ electrolytes. c) Galvanostatic charge/discharge curves in TEA $\mathrm{BF}_{4} / \mathrm{MeCN}$ at current rates from $0.5 \mathrm{Ag}^{-1}$ to $32 \mathrm{~A} \mathrm{~g}^{-1}$ (inset: Low internal resistance of the $1 \mathrm{~T}$ $\mathrm{MoS}_{2}$ electrodes in $1 \mathrm{M} \mathrm{TEA} \mathrm{BF} / \mathrm{MeCN}$ at a current density of $\left.32 \mathrm{~A} \mathrm{~g}^{-1}\right)$. Figure $4 \mathrm{a}-\mathrm{c}$ are reproduced from reference 70 (Copyright 2015 Nature Publishing Group). Electrochemical characterization of metallic $\mathrm{VS}_{2}$ sheets for supercapacitors: d) Schematic illustration of the inplane configuration of the as-fabricated supercapacitor using a $\mathrm{VS}_{2}$ thin film electrode. e) $\mathrm{CV}$ curves at different scanning rates $\left(20,100\right.$, and $\left.200 \mathrm{mV} \mathrm{s}^{-1}\right)$. f) Cycle performance of the supercapacitor, showing negligible degradations in the coulomb efficiency (left side y-axis) and specific capacitance (right side $y$-axis). Figure $4 \mathrm{~d}-\mathrm{f}$ are reproduced with permission from reference 74 (Copyright 2011 American Chemical Society). 


\section{WILEY-VCH}

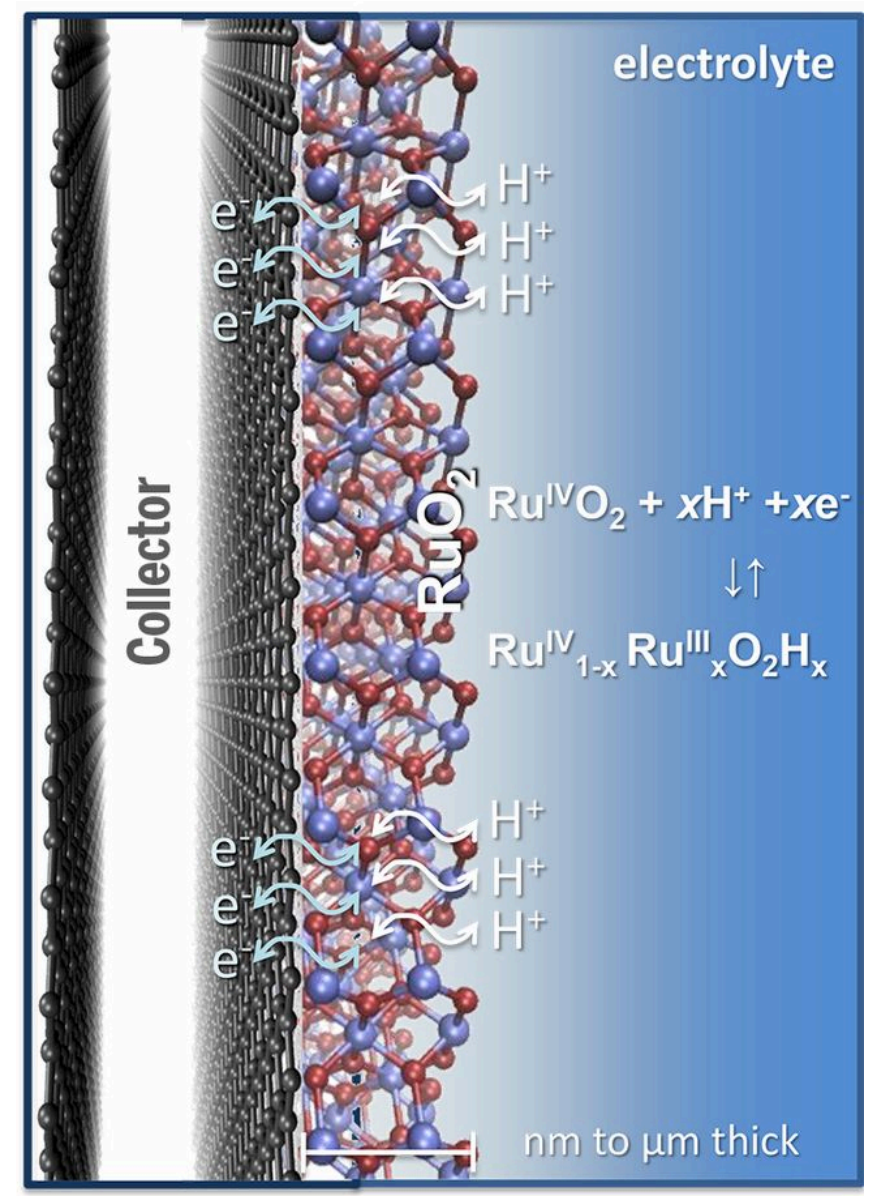

Figure 5. Charge transfer near the surface of the electrode for pseudocapacitors. Reproduced with permission from reference 4 (Copyright 2015 AAAS). 

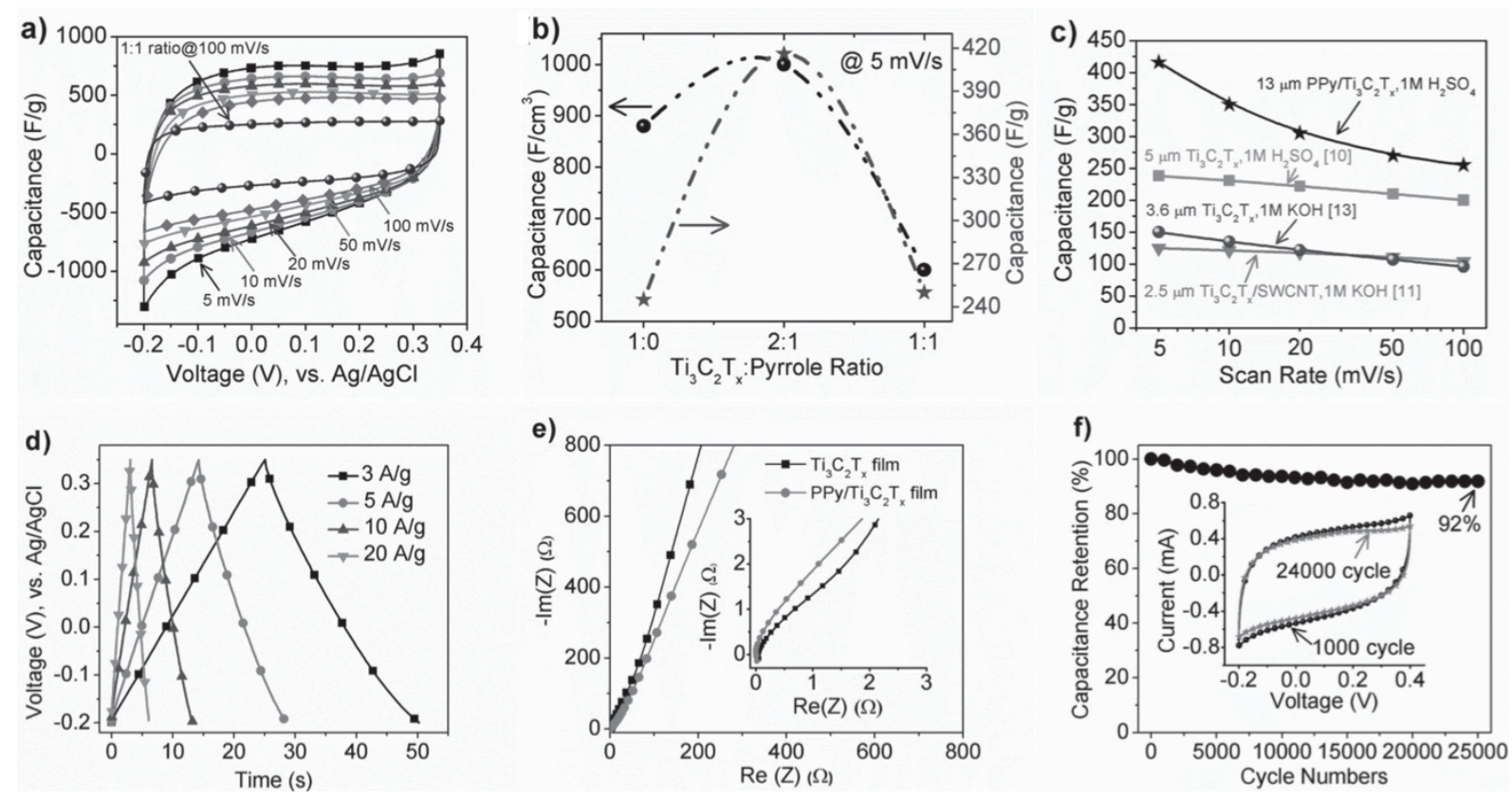

Figure 6. Electrochemical characterization of $\mathrm{PPy} / \mathrm{Ti}_{3} \mathrm{C}_{2} \mathrm{~T}_{x}$ composites for supercapacitors: a) CV curves of $\mathrm{PPy} / \mathrm{Ti}_{3} \mathrm{C}_{2} \mathrm{~T}_{x}$ (1:2) film at various scan rates. b) Effect of pyrrole loading on volumetric (left side y-axis) and gravemetric (right side y-axis) capacitance measured at $5 \mathrm{mV}$ $\mathrm{s}^{-1}$. c) Rate performance of tested compositions and comparisons of their capacitances with previously reported $\mathrm{Ti}_{3} \mathrm{C}_{2} \mathrm{~T}_{x}$ electrodes. d) Galvanostatic charge/discharge cycles of a $\mathrm{PPy} / \mathrm{Ti}_{3} \mathrm{C}_{2} \mathrm{~T}_{x}$ (1:2) film at various current densities. e) Impedance spectra of pristine $\mathrm{Ti}_{3} \mathrm{C}_{2} \mathrm{~T}_{x}$ and $\mathrm{PPy} / \mathrm{Ti}_{3} \mathrm{C}_{2} \mathrm{~T}_{x}$ (1:2) films. Inset: zoom-in of the high-frequency region. f) Cycle life performance showing high capacitance retention of the PPy/ $\mathrm{Ti}_{3} \mathrm{C}_{2} \mathrm{~T}_{x}(1: 2)$ film after 25000 cycles at $100 \mathrm{mV} \mathrm{s}^{-1}$. Inset shows that the shape of the $\mathrm{CV}$ was retained after cycling, confirming the high electrochemical stability of the PPy confined between the MXene layers. Reproduced with permission from reference 82 (Copyright 2016 Wiley). 


\section{WILEY-VCH}

\section{a)

\begin{tabular}{|l|} 
Cellulose paper (CP) \\
Graphite layer \\
Ni layer \\
$\mathrm{Co}_{2} \mathrm{NiO}_{4}$ layer \\
$\mathrm{PVA} / \mathrm{KOH}$ \\
AC layer
\end{tabular}

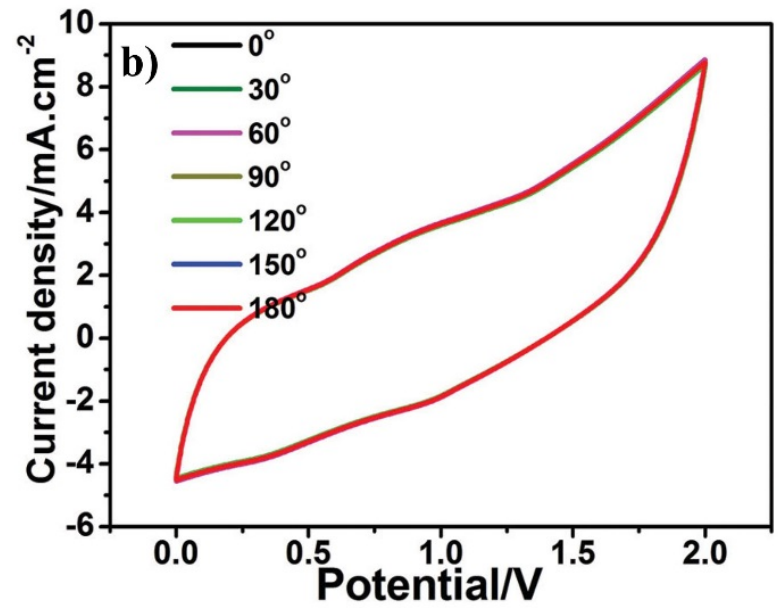

Figure 7. Cellulose paper (CP)-based asymmetrical, flexible thin film supercapacitors. a) Scheme of the assembled device using graphite $/ \mathrm{Ni} / \mathrm{Co}_{2} \mathrm{NiO}_{4}$ sheets-CP as positive electrode and graphite/Ni/active carbon-CP as negative electrode. b) $\mathrm{CV}$ curves of the device under various bending states at $50 \mathrm{mV} \mathrm{s}^{-1}$. c) Cycle performance of the device at different bending states for 20000 cycles at $100 \mathrm{mV} \mathrm{s}^{-1}$ and $10 \mathrm{~mA} \mathrm{~cm}^{-2}$. Reproduced with permission from reference 101 (Copyright 2014 Wiley). 


\section{WILEY-VCH}

a)

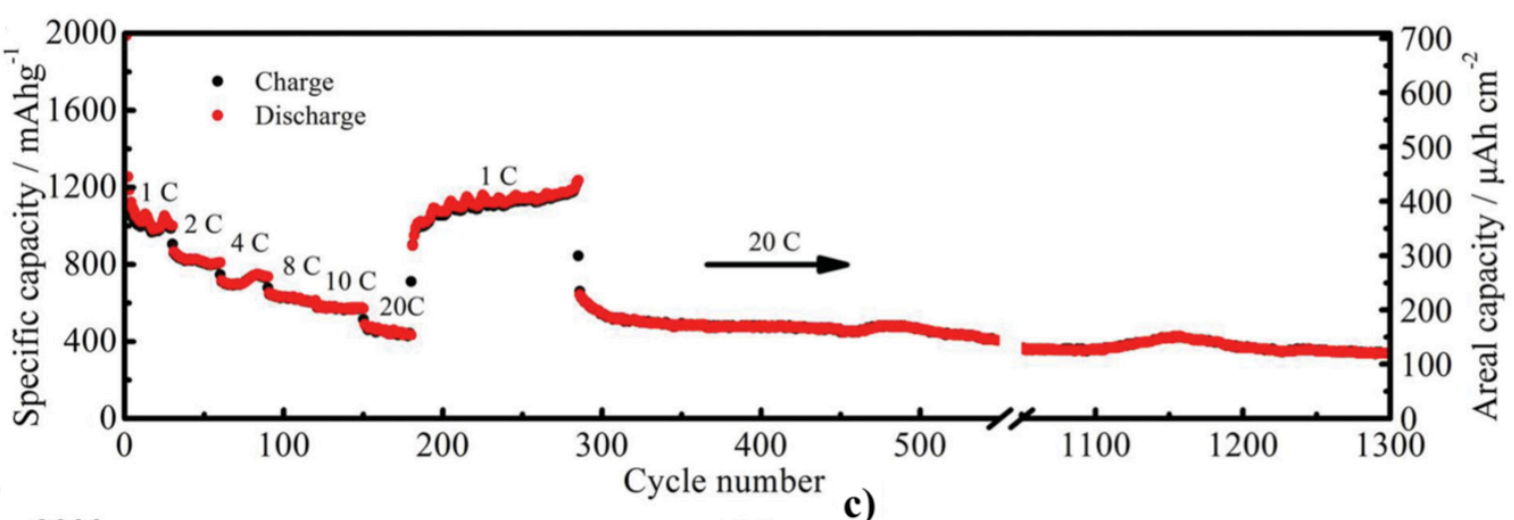

b)

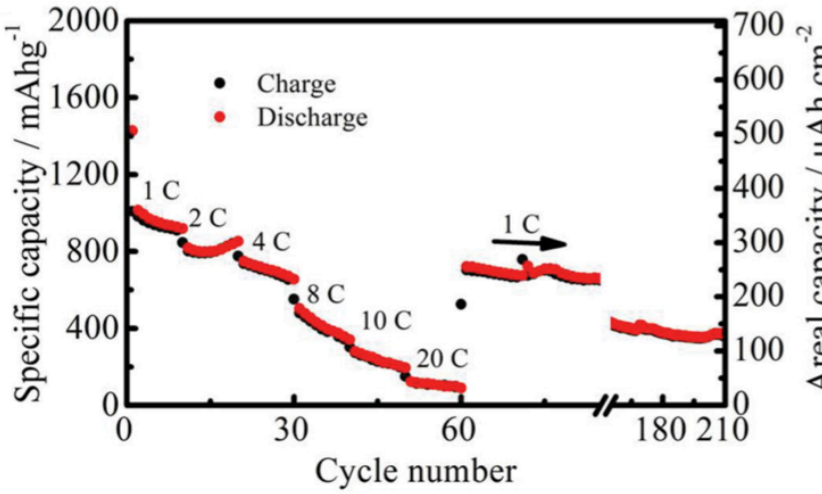

c)

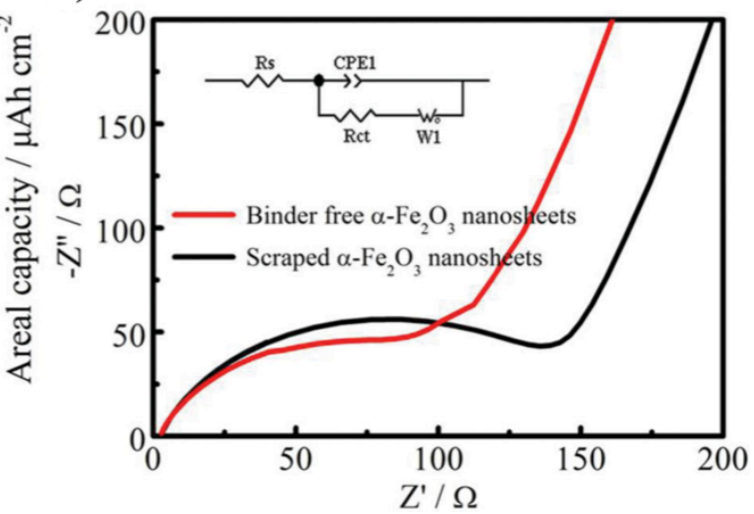

Figure 8. 3D hierarchical porous $\alpha-\mathrm{Fe}_{2} \mathrm{O}_{3}$ sheets for LIBs: a) Rate capabilities of binder-free electrodes. b) Rate capabilities of scraped layer electrodes. c) Electrochemical impedance spectra (EIS) of the fresh cells, with the inset showing the equivalent circuit used to interpret the data (Randles circuit: Rs-series resistance, CPE1-double layer capacitance, Rctcharge transfer resistance, and W1-Warburg impedance describing diffusion of ions). EIS was performed at an amplitude of $5 \mathrm{mV}(0.1-100 \mathrm{kHz})$. Reproduced with permission from reference 110 (Copyright 2015 Wiley). 
WILEY-VCH
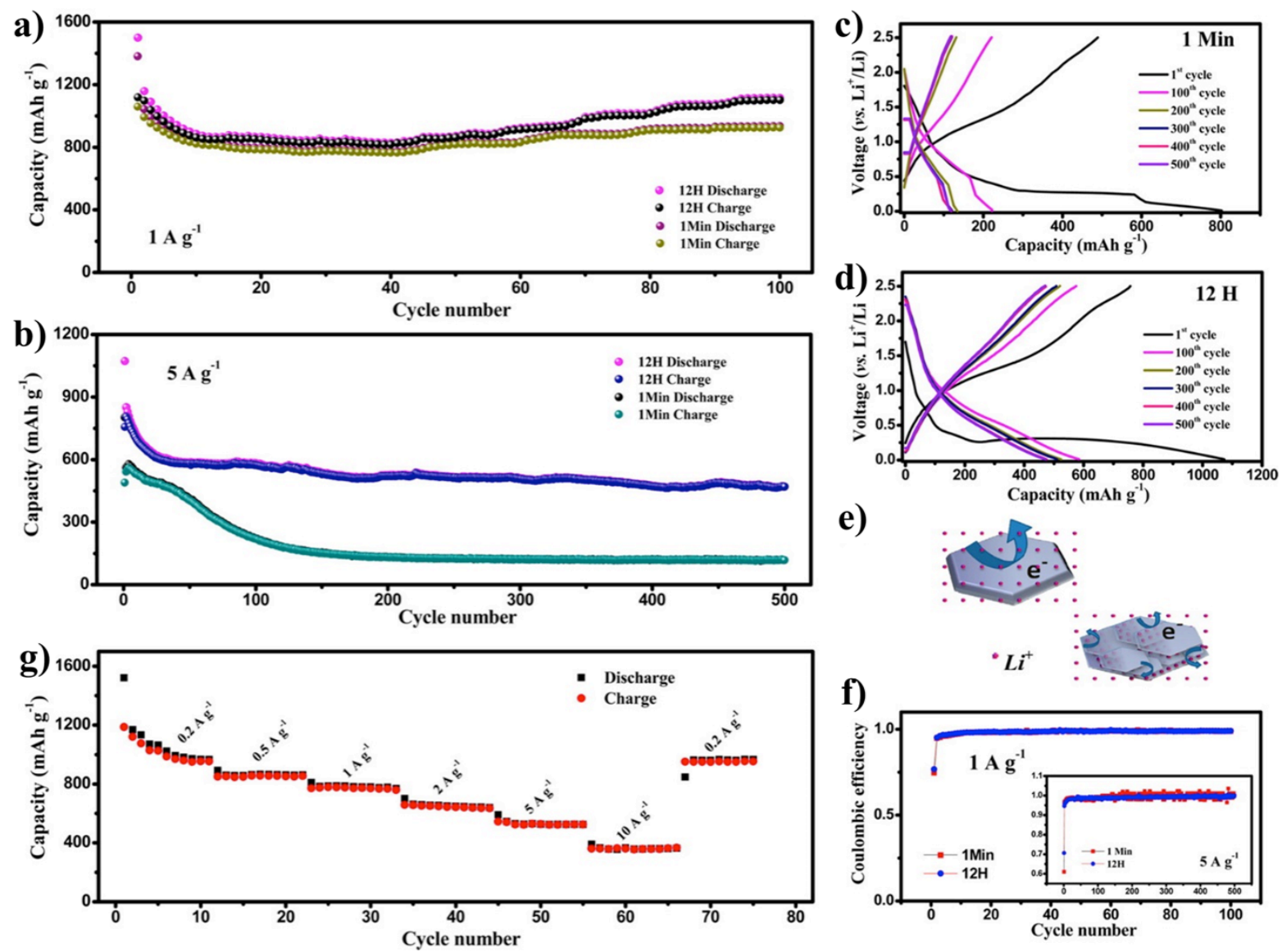

Figure 9. Electrochemical performances of the $\mathrm{Co}_{3} \mathrm{~V}_{2} \mathrm{O}_{8}$ sheets for LIBs. a) and b) Reversible charge/discharge capacities against cycle number for samples obtained at 1 min and $12 \mathrm{~h}$ at different current densities of 1 and $5 \mathrm{~A} \mathrm{~g}^{-1}$ in the voltage window of $0.01-2.5 \mathrm{~V}$. c) and d) Corresponding charge/discharge profiles in the first, $100^{\text {th }}, 200^{\text {th }}, 300^{\text {th }}, 400^{\text {th }}$, and $500^{\text {th }}$ cycles of the samples $1 \mathrm{~min}$ and $12 \mathrm{hrs}$ at the current density of $5 \mathrm{~A} \mathrm{~g} \mathrm{~g}^{-1}$. e) Schematic illustration of electron-transfer pathways for two samples. f). Corresponding Coulombic efficiencies. g) Rate performance of the $\mathrm{Co}_{3} \mathrm{~V}_{2} \mathrm{O}_{8}$ sheets obtained at $12 \mathrm{hrs}$. Reproduced with permission from reference 117 (Copyright 2014 American Chemical Society). 


\section{WILEY-VCH}
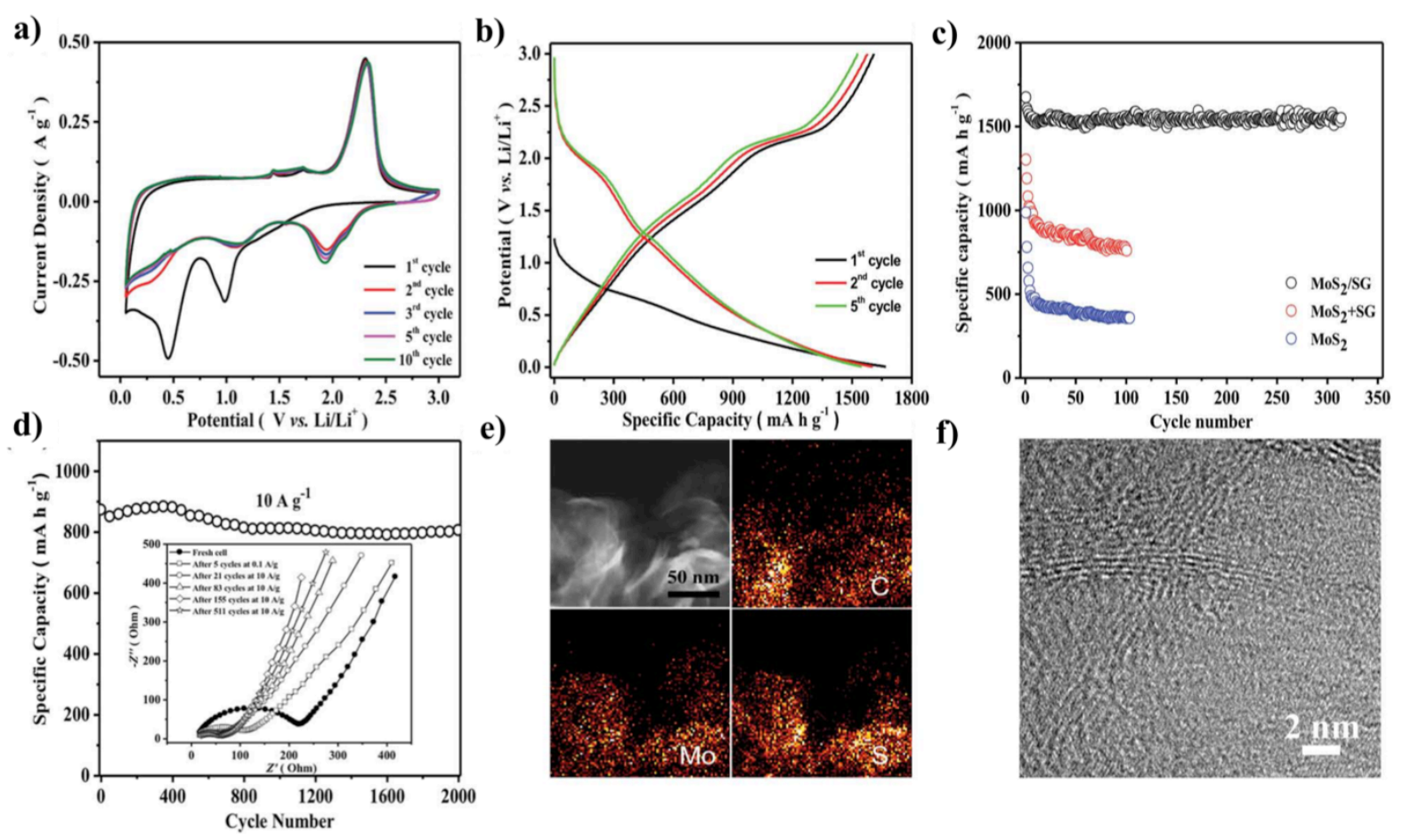

Figure 10. Electrochemical and microscopic characterization of $\mathrm{MoS}_{2} / \mathrm{S}$-doped RGO electrodes for LIBs. a) CV plots of a representative $\mathrm{MoS}_{2} / \mathrm{S}$-doped RGO composite electrode at a sweep rate of $0.1 \mathrm{mV} \mathrm{s}^{-1}$ between 3.0 and $0.005 \mathrm{~V}$. The two peaks at 0.99 and $0.45 \mathrm{~V}$ for the initial cycle correspond to the $\mathrm{Li}^{+}$intercalation process forming $\mathrm{Li}_{\mathrm{x}} \mathrm{MoS}_{2}$, and the further conversion to Mo embedded in $\mathrm{Li}_{2} \mathrm{~S}$ matrix, respectively. b) Galvanostatic charge/discharge curves of a composite electrode at a current densities of $0.1 \mathrm{~A} \mathrm{~g} \mathrm{~g}^{-1}$ between 3.0 and $0.005 \mathrm{~V}$. The low open circuit voltage (OCV) might be due to self-discharging. c) Comparison of cycling stability of $\mathrm{MoS}_{2} / \mathrm{S}$-doped RGO composites with pure $\mathrm{MoS}_{2}$ and physically mixed $\mathrm{MoS}_{2}$ and S-doped RGO at a current density of $0.1 \mathrm{~A} \mathrm{~g}^{-1}$. d) Long-term cycling performance of $\mathrm{MoS}_{2} / \mathrm{S}$-doped RGO composites at a high current density of $10 \mathrm{~A} \mathrm{~g}^{-1}$ (inset: the Nyquist plot of the composite electrode at frequencies from $100 \mathrm{kHz}$ to $0.01 \mathrm{~Hz}$ at different cycling status). e) high-magnification high angle annular dark field scanning transmission electron microscopy (HAADF-STEM) image of $\mathrm{MoS}_{2} / \mathrm{S}$-doped RGO composite after cycling test and the corresponding energy-dispersive X-ray spectroscopy (EDS) mapping of the elements $\mathrm{C}$, Mo, and S. f) High-resolution TEM images of as-synthesized $\mathrm{MoS}_{2} / \mathrm{S}$-doped RGO composites after cycling test. Reproduced with permission from reference 152 (Copyright 2015 Wiley). 


\section{WILEY-VCH}
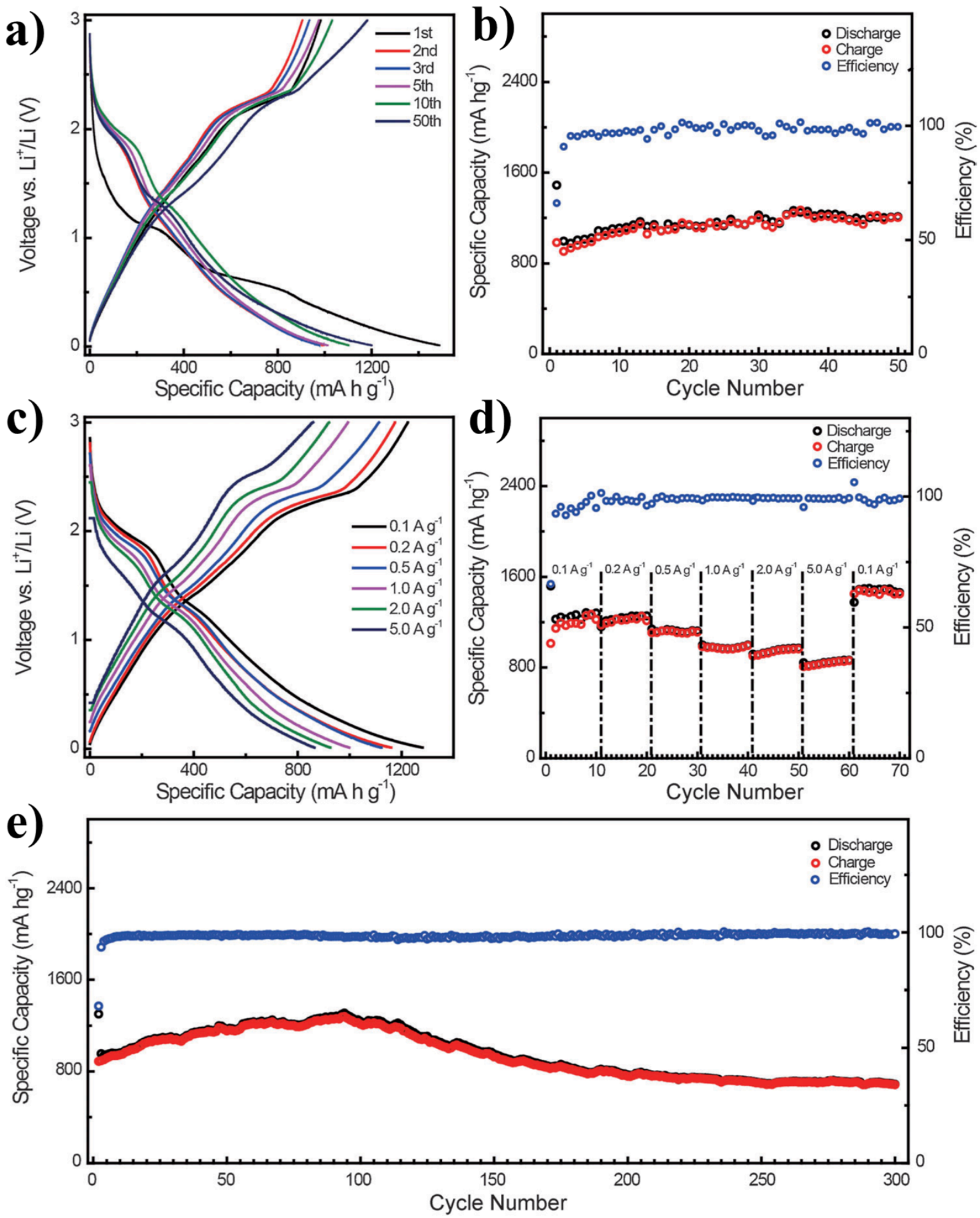

Figure 11. Electrochemical measurement of CNFs@MoS2 for LIBs. a) Galvanostatic discharge-charge (GDC) profiles. b). Cycling performance of CNFs@ $\mathrm{MoS}_{2}$ at $0.1 \mathrm{~A} \mathrm{~g}^{-1}$. c) GDC profiles and d) cycling performance of CNFs@MoS $\mathrm{MoS}_{2}$ at different current densities. e) Long life cycling performance of CNFs@ $\mathrm{MoS}_{2}$ at $1 \mathrm{~A} \mathrm{~g}^{-1}$. Reproduced with permission from reference 169 (Copyright 2014 Wiley). 


\section{WILEY-VCH}
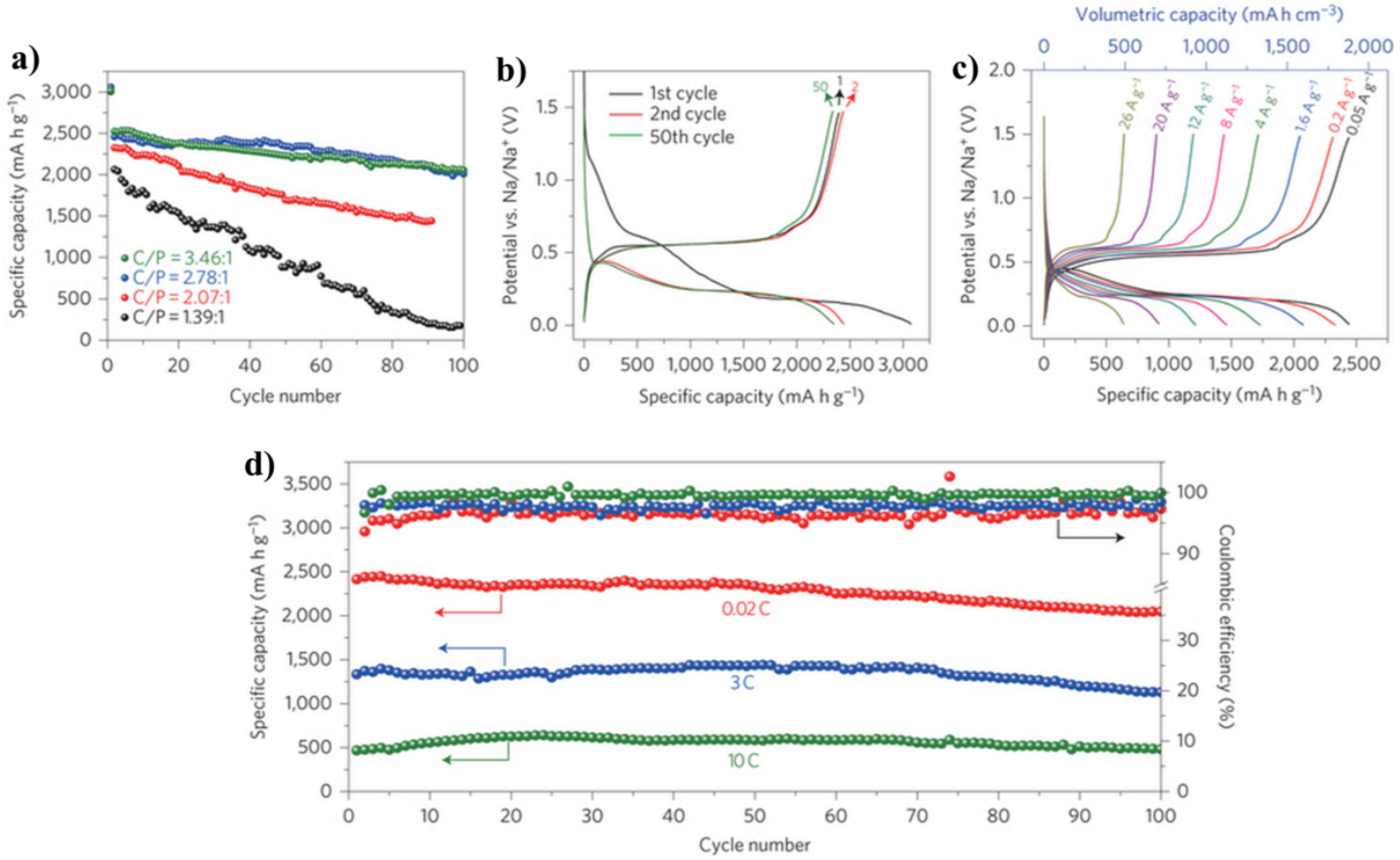

Figure 12. Electrochemical measurement of the phosphorene-graphene anode for SIBs. a). Reversible desodiation capacities for the first 100 galvanostatic cycles of various phosphorene-graphene electrodes with different carbon/phosphorus mole ratios $(\mathrm{C} / \mathrm{P})$ of 1.39 , 2.07, 2.78 and 3.46, between 0.02 and $1.5 \mathrm{~V}$ at a current density of $0.05 \mathrm{~A} \mathrm{~g}^{-1}$. b). Galvanostatic discharge-charge curves of the phosphorene-graphene $(48.3 \mathrm{wt} \% \mathrm{P})$ anode plotted for the first, second and $50^{\text {th }}$ cycles. c). Volumetric and mass capacities at different current densities (from 0.05 to $26 \mathrm{~A} \mathrm{~g}^{-1}$ ). d). Reversible desodiation capacity and Coulombic efficiency for the first 100 galvanostatic cycles of the phosphorene/graphene $(48.3 \mathrm{wt} \% \mathrm{P})$ hybrid anode tested at different current densities. Reproduced with permission from reference 29 (Copyright 2015 Nature Publishing Group). 


\section{WILEY-VCH}

Table 1. Properties typical 2D graphene analogues.

\begin{tabular}{|c|c|c|c|}
\hline Materials & Band gap (eV) & Mobility $\left(\mathrm{cm}^{2} \mathrm{~V}^{-1} \mathrm{~s}^{-1}\right)$ & Surface area $\left(\mathrm{m}^{2} \mathrm{~g}^{-1}\right)$ \\
\hline $\begin{array}{l}\mathrm{MoS}_{2} \\
\text { (TMDs) }\end{array}$ & 1.8 (Ref. 18) & 148 (single-layer, $300 \mathrm{~K}$, Ref. & $\begin{array}{c}180-240 \\
\text { (hydrothermal, Ref. 27) }\end{array}$ \\
\hline $\begin{array}{l}\mathrm{MnO}_{2} \\
(\mathrm{TMOs})\end{array}$ & 2.1 (optical, Ref. 20) & - & $\begin{array}{c}257.5 \\
\text { (wet chemistry, Ref. 28) }\end{array}$ \\
\hline Phosphorene & 1.45 (Ref. 21) & 1000 (few-layer, Ref. 22) & $\begin{array}{c}367 \\
\text { (liquid phase exfoliation, Ref. } \\
29 \text { ) }\end{array}$ \\
\hline MXene & $\begin{array}{l}\text { Metallic or narrow band gap } \\
\text { semiconductor (Ref. 23) }\end{array}$ & $0.7 \pm 0.2$ (Ref. 24$)$ & $\begin{array}{c}23 \\
\text { (Ref. 30) }\end{array}$ \\
\hline Silicene & $1.9 \times 10^{-3}($ Ref. 25$)$ & 100 (RT, Ref. 26) & - \\
\hline
\end{tabular}


Table 2. Summary of supercapacitor performance of 2D graphene analogues.

\begin{tabular}{|c|c|c|c|c|c|}
\hline Ref. & Electrodes & Electrolyte & $\begin{array}{c}\text { Electrode } \\
\text { configuration }\end{array}$ & $\begin{array}{c}\text { Supercapacitor } \\
\text { performance }\end{array}$ & Cycle performance \\
\hline 70 & Metallic $1 \mathrm{~T} \mathrm{MoS}_{2}$ & $\begin{array}{c}0.5 \mathrm{M} \mathrm{H}_{2} \mathrm{SO}_{4}, \\
\mathrm{Li}_{2} \mathrm{SO}_{4}, \mathrm{Na}_{2} \mathrm{SO}_{4}, \\
\mathrm{~K}_{2} \mathrm{SO}_{4} \\
\mathrm{KCl} \text { or KBr} \\
1 \mathrm{M} \mathrm{TEA} \mathrm{BF} \mathrm{BF}_{4} \text { or } \\
\text { EMIM BF} 4 \text { in } \\
\text { acetonitrile }\end{array}$ & Three/Two & $\begin{array}{l}\text { Volumetric } \\
\text { capacitance }(400 \sim \\
\left.700 \mathrm{~F} \mathrm{~cm}^{-3}\right)\end{array}$ & $\begin{array}{c}>90 \% \text { retained after } \\
5000 \text { cycles }\end{array}$ \\
\hline 74 & Metallic $\mathrm{VS}_{2}$ & $\mathrm{BMIMBF}_{4}-\mathrm{PVA}$ & Two & $\begin{array}{c}\text { Capacitance (4760 } \\
\left.\qquad \mu \mathrm{F} \mathrm{cm}^{-2}\right)\end{array}$ & $\begin{array}{l}\text { No obvious } \\
\text { degradation after } \\
1000 \text { cycles }\end{array}$ \\
\hline 76 & $\begin{array}{l}\mathrm{Co}_{3} \mathrm{O}_{4} \text { (anode) } \\
\text { activated carbon } \\
\quad \text { (cathode) }\end{array}$ & $2 \mathrm{M} \mathrm{KOH}$ & Two/Three & $\begin{array}{l}\text { Two-electrode: } \\
\text { Capacitance }(108 \mathrm{~F} \\
\left.\mathrm{g}^{-1}\right) \text { Energy density } \\
\left(134 \mathrm{Wh} \mathrm{kg}^{-1}\right) ; \\
\text { Three-electrode: } \\
\text { Capacitance }(1782 \mathrm{~F} \\
\left.\mathrm{g}^{-1} \text { at } 1.8 \mathrm{~A} \mathrm{~g}^{-1}\right)\end{array}$ & $\begin{array}{c}\text { Three-electrode: } \\
>90 \% \text { retained after } \\
2000 \text { cycles at } 30 \\
\mathrm{~mA} \mathrm{~cm}^{-2} ; \\
\text { Two-electrode: } \\
>80 \% \text { retained after } \\
800 \text { cycles at } 30 \mathrm{~mA} \\
\mathrm{~cm}^{-2}\end{array}$ \\
\hline 77 & $\mathrm{Co}_{3} \mathrm{~V}_{2} \mathrm{O}_{8}$ & $3 \mathrm{M} \mathrm{KOH}$ & Three & $\begin{array}{l}\text { Capacitance }(739 \mathrm{~F} \\
\left.\mathrm{g}^{-1} \text { at } 0.5 \mathrm{~A} \mathrm{~g}^{-1}\right)\end{array}$ & $\begin{array}{c}>95.3 \% \text { retained } \\
\text { after } 2000 \text { cycles } 0.5 \\
\mathrm{~A} \mathrm{~g}^{-1}\end{array}$ \\
\hline 78 & $\begin{array}{c}\beta-\mathrm{Co}(\mathrm{OH})_{2} \\
\text { (cathode) } \\
\text { Nitrogen-doped } \\
\text { graphene } \\
\text { (anode) }\end{array}$ & $\begin{array}{l}\text { PVA solid } \\
\text { electrolyte } \\
(2 \mathrm{M} \mathrm{KOH})\end{array}$ & Two & $\begin{array}{c}\text { Energy density }(98.9 \\
\left.\mathrm{Wh} \mathrm{kg}^{-1}\right) \\
\text { Power density } \\
\left(17981 \mathrm{~W} \mathrm{~kg}^{-1}\right)\end{array}$ & $\begin{array}{c}93.2 \% \text { retained after } \\
10000 \text { cycles } 20 \mathrm{mV} \\
\mathrm{s}^{-1}\end{array}$ \\
\hline 84 & $\begin{array}{l}\text { Porous graphene } \\
\quad \text { (anode) } \\
\mathrm{Ni}(\mathrm{OH})_{2} / \text { graphene } \\
\quad \text { (cathode) }\end{array}$ & $6 \mathrm{M} \mathrm{KOH}$ & Two & $\begin{array}{l}\text { Capacitance }(218.4 \\
\left.\mathrm{F} \mathrm{g}^{-1}\right) \\
\text { Energy density }(77.8 \\
\left.\mathrm{Wh} \mathrm{kg}^{-1}\right)\end{array}$ & $\begin{array}{c}94.3 \% \text { retained after } \\
3000 \text { cycles at } 100 \\
\mathrm{mV} \mathrm{s}^{-1}\end{array}$ \\
\hline 85 & $\begin{array}{c}\mathrm{RGO} / \mathrm{MnO}_{2} \text { (anode) } \\
\mathrm{RGO} / \mathrm{MoO}_{3} \\
\text { (cathode) }\end{array}$ & $1 \mathrm{M} \mathrm{Na}_{2} \mathrm{SO}_{4}$ & Two & $\begin{array}{c}\text { Capacitance }(307 \mathrm{~F} \\
\left.\mathrm{g}^{-1} \text { at } 0.2 \mathrm{~A} \mathrm{~g}^{-1}\right) \\
\text { Energy density }(42.6 \\
\left.\mathrm{Wh} \mathrm{kg}^{-1}\right) \\
\text { Power density }(276 \\
\left.\mathrm{W} \mathrm{kg}^{-1}\right)\end{array}$ & $\begin{array}{c}\text { Capacitance } \\
\text { increased after } 1000 \\
\text { cycles at } 50 \mathrm{mV} \mathrm{s}^{-1}\end{array}$ \\
\hline 86 & RGO/TMDs & PVA- $\mathrm{H}_{2} \mathrm{SO}_{4}$ & Two & $\begin{array}{c}\text { Volumetric } \\
\text { capacitance }(16.5 \mathrm{~F} \\
\left.\mathrm{cm}^{-3} \text { at } 1 \mu \mathrm{A}\right)\end{array}$ & $\begin{array}{l}80 \% \text { retained after } \\
1000 \text { cycles }\end{array}$ \\
\hline 87 & $\begin{array}{c}\mathrm{Co}_{(1-} \\
\left.{ }_{x}\right) \mathrm{Ni}_{\mathrm{x}}(\mathrm{OH})_{2} / \mathrm{RGO}\end{array}$ & $1 \mathrm{M} \mathrm{KOH}$ & Three & $\begin{array}{l}\text { Capacitance }(1075, \\
1359 \mathrm{~F} \mathrm{~g}^{-1} \text { at } 100,1 \\
\left.\mathrm{~A} \mathrm{~g}^{-1}, \text { respectively }\right)\end{array}$ & $\begin{array}{c}72 \% \text { retained after } \\
7000 \text { cycles at } 20 \mathrm{~A} \\
\mathrm{~g}^{-1}\end{array}$ \\
\hline 88 & MXene/CNTs & $1 \mathrm{M} \mathrm{MgSO}_{4}$ & Three & $\begin{array}{c}\text { Volumetric } \\
\text { capacitance }(350 \mathrm{~F} \\
\left.\mathrm{cm}^{-3} \text { at } 5 \mathrm{~A} \mathrm{~g}^{-1}\right)\end{array}$ & $\begin{array}{c}\text { No degradation after } \\
10000 \text { cycles at } 10 \\
\mathrm{~A} \mathrm{~g}^{-1}\end{array}$ \\
\hline 89 & $\mathrm{CNT} @ \mathrm{Ni}_{3} \mathrm{~S}_{2}$ & $2 \mathrm{M} \mathrm{KOH}$ & Three & $\begin{array}{l}\text { Capacitance }(514, \\
362 \mathrm{~F} \mathrm{~g}^{-1} \text { at } 4,13.3 \\
\mathrm{~A} \mathrm{~g}^{-1}, \text { respectively }\end{array}$ & $\begin{array}{c}88 \% \text { retained after } \\
1500 \text { cycles at } 5.3 \mathrm{~A} \\
\mathrm{~g}^{-1}\end{array}$ \\
\hline 90 & $\begin{array}{c}\text { NiMn double } \\
\text { hydroxide/CNT } \\
\text { (anode) } \\
\text { RGO/CNT } \\
\text { (cathode) }\end{array}$ & Nafion/KOH & Two & $\begin{array}{c}\text { Energy density }(88.3 \\
\left.\mathrm{Wh} \mathrm{kg}^{-1}\right) \\
\text { Power density }(850 \\
\left.\mathrm{W} \mathrm{kg}^{-1}\right)\end{array}$ & $\begin{array}{c}>94 \% \text { retained after } \\
1000 \text { cycles at } 10 \mathrm{~A} \\
\mathrm{~g}^{-1}\end{array}$ \\
\hline
\end{tabular}


$1 \mathrm{M} \mathrm{Na}_{2} \mathrm{SO}_{4}$ $\mathrm{PVA} / \mathrm{LiCl}$

$\mathrm{MnO}_{2} @$ PEDOT (a) $\mathrm{MnO}_{2}$

$\mathrm{MoS}_{2}$ /polypyrrole

95

100

102
94

82

97

98

93

(1)

7
$\mathrm{MoS}_{2} /$ polyaninline

MXene/polypyrrole

$\mathrm{NiMoO}_{4}$ on

conductive

substrates (Anode)

activated carbon

(cathode)

$\mathrm{Ni}(\mathrm{OH})_{2} /$ ultrathingraphite foam

(Anode);

Activated

microwave

exfoliated graphite

oxide (Cathode)

FeOOH (anode)

Co-Ni double

hydroxides (cathod)
$\mathrm{Li}_{2} \mathrm{Co}_{2}\left(\mathrm{MoO}_{4}\right)_{3}$ on conductive
substrates

Nickel-cobaltaluminum layered hydroxides
$0.5 \mathrm{M} \mathrm{Na}_{2} \mathrm{SO}_{4}$

$0.5 \mathrm{M} \mathrm{H}_{2} \mathrm{SO}_{4}$

$1 \mathrm{M} \mathrm{H}_{2} \mathrm{SO}_{4}$

$2 \mathrm{M} \mathrm{KOH}$

$6 \mathrm{M} \mathrm{KOH}$

$3 \mathrm{M} \mathrm{KOH}$

Several alkaline electrolytes

$2 \mathrm{M} \mathrm{NaOH}$
Three/Two

energy density (27.2

Two

Two

Two

Three
Two

Energy density (86.4Wh kg-1) Power density (11.6

Energy density (60.9

$\mathrm{Wh} \mathrm{kg}^{-1}$ )

Power density (850

W kg ${ }^{-1}$ )

Energy density (6.9

Wh kg ${ }^{-1}$ )

Power density (44

$\mathrm{kW} \mathrm{kg}{ }^{-1}$ )

Three

Capacitance (1055, $700 \mathrm{~F} \mathrm{~g}^{-1}$ at $1,50 \mathrm{~A}$ $\mathrm{g}^{-1}$, respectively)

$91 \%$ retained after 10000 cycles at 30 $\mathrm{A} \mathrm{g}^{-1}$

Three 10000 cycles at $5 \mathrm{~A}$ $\mathrm{g}^{-1}$

$63.2 \%$ retained after 10000 cycles at $5 \mathrm{~A}$ $\mathrm{g}^{-1}$

$92.3 \%$ retained after 3000 cycles at 100 $\mathrm{mV} \mathrm{s}^{-1}$

Capacitance $(1289, \quad 82.2 \%$ retained after
Capacitance (634.5

$\mathrm{F} \mathrm{g}^{-1}$ at $\left.2.5 \mathrm{~A} \mathrm{~g}^{-1}\right)$

Capacitance $(87.1 \mathrm{~F}$

$\mathrm{g}^{-1}$ at $\left.1.25 \mathrm{~A} \mathrm{~g}^{-1}\right)$

Wh kg-1) power

density $(979.7 \mathrm{~W}$

$\mathrm{kg}^{-1}$ )

Energy density (47.8

Wh kg $\left.{ }^{-1}\right)$

Power density (180

$\mathrm{W} \mathrm{kg}^{-1}$ )

Capacitance (695, $500 \mathrm{~F} \mathrm{~g}^{-1}$ at $0.5,10$

$\mathrm{A} \mathrm{g}^{-1}$, respectively)

Energy density (83.3

Wh kg-1)

Power density

(3332 $\mathrm{W} \mathrm{kg}^{-1}$ )

Capacitance $(180 \mathrm{~F}$ $\mathrm{g}^{-1}$ at $50 \mathrm{~A} \mathrm{~g}^{-1}$ )

Energy density (106

Wh $\mathrm{kg}^{-1}$ )

Power density (106

$\mathrm{kW} \mathrm{kg}^{-1}$ )

Volumetric capacitance $(1000 \mathrm{~F}$ $\mathrm{cm}^{-3}$ )

$$
\mathrm{kW} \mathrm{kg}^{-1} \text { ) }
$$

Slight decrease after 3000 cycles at $20 \mathrm{~A}$ $\mathrm{g}^{-1}$;

$95.2 \%$ retained after 3000 cycles at 6.25 $\mathrm{A} \mathrm{g}^{-1}$

$91.3 \%$ retained after 5000 cycles at $3 \mathrm{~A}$ $\mathrm{g}^{-1}$

$85 \%$ retained after 4000 cycles at $1 \mathrm{~A}$ $\mathrm{g}^{-1}$

$91 \%$ retained after 4000 cycles at $10 \mathrm{~A}$ $\mathrm{g}^{-1}$

$92 \%$ retained after 25000 cycles at 100 $\mathrm{mV} \mathrm{s}^{-1}$

$85.7 \%$ retained after $738 \mathrm{~F} \mathrm{~g}^{-1}$ at $1,30 \mathrm{~A} \quad 2000$ cycles at $5 \mathrm{~A}$ $\mathrm{g}^{-1}$, respectively) $\mathrm{g}^{-1}$

RGO-reduced graphene oxide; CNT-carbon nanotube 
WILEY-VCH

Table 3. Summary of battery performance of 2D graphene analogues.

\begin{tabular}{|c|c|c|c|c|c|}
\hline Ref. & Electrodes & Electrolyte & $\begin{array}{l}\text { Battery } \\
\text { type }\end{array}$ & $\begin{array}{c}\text { Battery } \\
\text { performance }\end{array}$ & $\begin{array}{c}\text { Cycle } \\
\text { performance }\end{array}$ \\
\hline 110 & $\begin{array}{c}\alpha-\mathrm{Fe}_{2} \mathrm{O}_{3} \text { (anode) } \\
\text { Home-made } \mathrm{LiFePO}_{4} \text { (cathode) }\end{array}$ & $\begin{array}{c}1 \mathrm{M} \mathrm{LiPF}_{6} \text { in a } 1: 1 \\
\text { mixture of ethylene } \\
\text { carbonate and dimethyl } \\
\text { carbonate }\end{array}$ & LIBs & $\begin{array}{c}\text { Specific } \\
\text { capacity }(827.9 \\
\mathrm{mAh} \mathrm{g}^{-1} \text { at } 2.01 \\
\left.\mathrm{~A} \mathrm{~g}^{-1}\right)\end{array}$ & $\begin{array}{l}\text { Increased to } \\
877.7 \mathrm{mAh} \mathrm{g}^{-1} \\
\text { after } 1000 \mathrm{cycles}^{-1} \\
\text { at } 2.01 \mathrm{~A} \mathrm{~g}^{-1}\end{array}$ \\
\hline 112 & $\mathrm{~V}_{2} \mathrm{O}_{5}$ & $\begin{array}{l}1 \mathrm{M} \mathrm{LiPF}_{6} \text { in a } 1: 1(\mathrm{v} / \mathrm{v}) \\
\text { mixture of ethylene } \\
\text { carbonate and dimethyl } \\
\text { carbonate }\end{array}$ & LIBs & $\begin{array}{c}\text { Specific } \\
\text { capacity }(219 \\
\mathrm{mAh}^{-1} \text { at } 1 \mathrm{~A} \\
\left.\mathrm{~g}^{-1}\right)\end{array}$ & $\begin{array}{l}78 \% \text { retained } \\
\text { after } 100 \text { cycles } \\
\text { at } 0.5 \mathrm{~A} \mathrm{~g}^{-1}\end{array}$ \\
\hline 113 & $\mathrm{Nb}_{2} \mathrm{O}_{5}$ & $\begin{array}{l}1 \mathrm{M} \mathrm{LiPF}_{6} \text { in a } 1: 1: 1 \\
\text { mixture of ethylene } \\
\text { carbonate/dimethyl } \\
\text { carbonate/diethyl } \\
\text { carbonate }\end{array}$ & LIBs & $\begin{array}{c}\text { Specific } \\
\text { capacity (90, } \\
184 \mathrm{mAh} \mathrm{g}^{-1} \text { at } \\
1,0.2 \mathrm{~A} \mathrm{~g}^{-1} \\
\text { respectively) }\end{array}$ & $\begin{array}{c}77.8 \% \text { retained } \\
\text { after } 200 \text { cycles } \\
\text { at } 5 \mathrm{C}\end{array}$ \\
\hline 114 & $\mathrm{TiO}_{2}$ & $\begin{array}{c}1 \mathrm{M} \mathrm{LiPF}_{6} \text { in a } 1: 1 \\
\text { mixture of ethylene } \\
\text { carbonate and diethyl } \\
\text { carbonate }\end{array}$ & LIBs & $\begin{array}{c}\text { Specific } \\
\text { capacity } \\
(224,192,170 \\
\mathrm{mAh} \mathrm{g}^{-1} \text { at } 0.5 \\
1,5 \mathrm{C} \\
\text { respectively) }\end{array}$ & $\begin{array}{c}87.5 \% \text { retained } \\
\text { after } 100 \text { cycles } \\
\text { at } 1 \mathrm{C}\end{array}$ \\
\hline 115 & $\mathrm{TiO}_{2}(\mathrm{~B})$ & $\begin{array}{c}1 \mathrm{M} \mathrm{LiPF}_{6} \text { in a } 1: 1(\mathrm{v} / \mathrm{v}) \\
\text { mixture of ethylene } \\
\text { carbonate and dimethyl } \\
\text { carbonate }\end{array}$ & LIBs & $\begin{array}{c}\text { Specific } \\
\text { capacity }(182, \\
202,216 \mathrm{mAh} \\
\mathrm{g}^{-1} \text { at } 5,2,1 \mathrm{C}, \\
\text { respectively) }\end{array}$ & $\begin{array}{c}87.9 \% \text { retained } \\
\text { after } 400 \text { cycles } \\
\text { at } 5 \mathrm{C}\end{array}$ \\
\hline 116 & Anatase $/ \mathrm{TiO}_{2}-\mathrm{B}$ & $\begin{array}{l}1 \mathrm{M} \mathrm{LiPF}_{6} \text { in a } 1: 1(\mathrm{v} / \mathrm{v}) \\
\text { mixture of ethylene } \\
\text { carbonate and dimethyl } \\
\text { carbonate }\end{array}$ & LIBs & $\begin{array}{c}\text { Specific } \\
\text { capacity }(221 \\
\mathrm{mAh} \mathrm{g}^{-1} \text { at } 1.7 \\
\left.\mathrm{~A} \mathrm{~g}^{-1}\right)\end{array}$ & $\begin{array}{c}86 \% \text { retained } \\
\text { after } 1000 \text { cycles } \\
\text { at } 1.7 \mathrm{~A} \mathrm{~g}^{-1}\end{array}$ \\
\hline 117 & $\mathrm{Co}_{3} \mathrm{~V}_{2} \mathrm{O}_{8}$ & $\begin{array}{c}1 \mathrm{M} \mathrm{LiPF}_{6} \text { in a } 1: 1(\mathrm{v} / \mathrm{v}) \\
\text { mixture of ethylene } \\
\text { carbonate and diethyl } \\
\text { carbonate }\end{array}$ & LIBs & $\begin{array}{c}\text { Specific } \\
\text { capacity }(525, \\
361 \mathrm{mAh} \mathrm{g}^{-1} \text { at } \\
5,10 \mathrm{~A} \mathrm{~g}^{-1} \\
\text { respectively) }\end{array}$ & $\begin{array}{l}1114 \mathrm{mAh} \mathrm{g}^{-1} \text { is } \\
\text { retained after } \\
100 \text { cycles at } 1 \mathrm{~A} \\
\mathrm{~g}^{-1}\end{array}$ \\
\hline 119 & $\mathrm{LiFePO}_{4}$ & $\begin{array}{c}1 \mathrm{M} \mathrm{LiPF}_{6} \text { in a } 1: 1: 1 \\
(\mathrm{v} / \mathrm{v} / \mathrm{v}) \text { mixture of } \\
\text { ethylene chloride/ } \\
\text { dimethyl chloride/diethyl } \\
\text { chloride }\end{array}$ & LIBs & $\begin{array}{l}\text { Specific } \\
\text { capacity }(107, \\
185 \mathrm{mAh} \mathrm{g}^{-1} \text { at } \\
20,0.1 \mathrm{C}, \\
\text { respectively) }\end{array}$ & $\begin{array}{l}97 \% \text { retained } \\
\text { after } 400 \text { cycles } \\
\text { at } 10 \mathrm{C}\end{array}$ \\
\hline 120 & $\mathrm{Na}_{1.08} \mathrm{~V}_{3} \mathrm{O}_{8}$ & $\begin{array}{c}1 \mathrm{M} \mathrm{LiPF}_{6} \text { in a } 1: 1(\mathrm{v} / \mathrm{v}) \\
\text { mixture of ethylene } \\
\text { carbonate and dimethyl } \\
\text { carbonate }\end{array}$ & LIBs & $\begin{array}{c}\text { Discharge } \\
\text { capacity }(200, \\
131.3,109.9, \\
94.2,72.5 \mathrm{mAh} \\
\mathrm{g}^{-1} \text { at } 0.4,10, \\
20,30,50 \mathrm{C}, \\
\text { respectively) }\end{array}$ & $\begin{array}{l}\text { No considerable } \\
\text { capacity loss } \\
\text { over } 200 \text { cycles } \\
\text { at } 1 \mathrm{~A} \mathrm{~g}^{-1}\end{array}$ \\
\hline 125 & $\mathrm{Fe}_{3} \mathrm{O}_{4}$ nanoparticles $/ \mathrm{MoS}_{2}$ & $\begin{array}{l}1 \mathrm{M} \mathrm{LiPF}_{6} \text { in a } 1: 1: 1 \\
\text { mixture of ethylene } \\
\text { carbonate/dimethyl } \\
\text { carbonate/diethyl } \\
\text { carbonate }\end{array}$ & LIBs & $\begin{array}{c}\text { Specific } \\
\text { capacity }(1033, \\
224 \mathrm{mAh} \mathrm{g}^{-1} \text { at } \\
2,10 \mathrm{~A} \mathrm{~g}^{-1} \\
\text { respectively) }\end{array}$ & $\begin{array}{c}\text { Increased } \\
\text { capacity after } \\
510 \text { cycles at } 2 \mathrm{~A} \\
\mathrm{~g}^{-1}\end{array}$ \\
\hline 130 & $\mathrm{Nb}_{2} \mathrm{CT}_{\mathrm{x}}$ or $\mathrm{V}_{2} \mathrm{CT}_{\mathrm{x}}$ & $\begin{array}{c}1 \mathrm{M} \mathrm{LiPF}_{6} \text { in a } 1: 1(\mathrm{w} / \mathrm{w}) \\
\text { mixture of ethylene } \\
\text { carbonate and diethyl } \\
\text { carbonate }\end{array}$ & LIBs & $\begin{array}{c}\text { Reversible } \\
\text { capacity }(170 \\
\text { and } 260 \mathrm{mAh} \\
\mathrm{g}^{-1} \text { at } 1 \mathrm{C} \text { for } \\
\mathrm{Nb}_{2} \mathrm{CT}_{\mathrm{x}} \text { and } \\
\mathrm{V}_{2} \mathrm{CT}_{\mathrm{x}},\end{array}$ & $\begin{array}{c}110 \text { and } 125 \\
\mathrm{mAh}^{-1} \text { were } \\
\text { obtained after } \\
150 \text { cycles at } 10 \\
\mathrm{C} \text { for } \mathrm{Nb}_{2} \mathrm{CT}_{\mathrm{x}} \\
\text { and } \mathrm{V}_{2} \mathrm{CT}_{\mathrm{x}}\end{array}$ \\
\hline
\end{tabular}




\section{WILEY-VCH}

$\mathrm{Nb}_{2} \mathrm{CT}_{\mathrm{x}} / \mathrm{CNT}$

$\mathrm{TiO}_{2}-\mathrm{B} / \mathrm{RGO}$
$\mathrm{TiO}_{2}-\mathrm{B}$ nanosheets/Anatase
nanocrystals/RGO
$\mathrm{ZnMn}_{2} \mathrm{O}_{4} / \mathrm{RGO}$ (anode)
$\mathrm{LiFePO}_{4}$ (cathode)

$\mathrm{MoS}_{2} / \mathrm{RGO}$

$\mathrm{MoS}_{2} /$ graphene

Black phosphorus/graphene

$\mathrm{MoS}_{2} / \mathrm{S}$-doped RGO

Metal carbide@N-doped carbon nanosheets

$\mathrm{MoS}_{2} / \mathrm{CNT}$

$\mathrm{MoS}_{2} / \mathrm{CNT}$

$\mathrm{TiO}_{2} / \mathrm{CNT}$

$\mathrm{SnO}_{2} / \mathrm{CNT}$
$1 \mathrm{M} \mathrm{LiPF}_{6}$ in a $1: 1: 1$ mixture of ethylene carbonate/diethyl carbonate

$1 \mathrm{M} \mathrm{LiPF}_{6}$ in a $1: 1(\mathrm{v} / \mathrm{v})$ mixture of ethylene carbonate and dimethyl carbonate

$1 \mathrm{M} \mathrm{LiPF}_{6}$ in a $1: 1(\mathrm{v} / \mathrm{v})$ mixture of ethylene carbonate and diethyl carbonate

$1 \mathrm{M} \mathrm{LiPF}_{6}$ in a $1: 1(\mathrm{w} / \mathrm{w})$ mixture of ethylene carbonate and dimethyl carbonate

$1 \mathrm{M} \mathrm{LiPF}_{6}$ in a $1: 1(\mathrm{v} / \mathrm{v})$ mixture of ethylene carbonate and diethyl carbonate

$1 \mathrm{M} \mathrm{LiPF}_{6}$ in a mixture of $1: 1: 1(\mathrm{v} / \mathrm{v} / \mathrm{v})$ ethylene carbonate/dimethyl carbonate/ethylmethyl carbonate

$1 \mathrm{M} \mathrm{LiPF}_{6}$ in a $1: 1(\mathrm{v} / \mathrm{v})$ mixture of ethylene carbonate and dimethyl carbonate

$1 \mathrm{M} \mathrm{LiPF}_{6}$ in a 1:1 mixture of ethylene carbonate and dimethyl carbonate

$1 \mathrm{M} \mathrm{LiPF}_{6}$ in a $1: 1(\mathrm{v} / \mathrm{v})$ mixture of ethylene carbonate and dimethyl carbonate

$1 \mathrm{M} \mathrm{LiPF}_{6}$ in a 40:60 (v/v) mixture of ethylene carbonate and dimethyl carbonate

$1 \mathrm{M} \mathrm{LiPF}_{6}$ in a $1: 1(\mathrm{w} / \mathrm{w})$ mixture of ethylene carbonate and diethyl carbonate carbonate/dimethyl

\section{LIBs}

respectively)

respectively

Specific

capacity ( 275

$\mathrm{mAh} \mathrm{g}^{-1}$ at $1 \mathrm{C}$ )

$80 \%$ retained

after 1000 cycles at $40 \mathrm{C}$

LIBs

Specific capacity $(160$, $154 \mathrm{mAh} \mathrm{g}^{-1}$ at $36,72 \mathrm{C}$,

respectively)

LIBs

Specific capacity $(122$, $109,90 \mathrm{mAh} \mathrm{g}^{-}$ ${ }^{1}$ at $0.5,1,2 \mathrm{C}$, respectively)

LIBs

LIBs

LIBs

LIBs

LIBs

LIBs

LIBs

LIBs

LIBs

$1 \mathrm{M} \mathrm{LiPF}_{6}$ in a $1: 1$ mixture of ethylene carbonate and diethyl
Specific capacity (598, $880,994 \mathrm{mAh}$ $\mathrm{g}^{-1}$ at $5,1,0.5$ $\mathrm{A} \mathrm{g}^{-1}$, respectively)

\section{Specific} capacity $\left(10^{\text {th }}\right.$ cycle capability of $466 \mathrm{mAh} \mathrm{g}^{-1}$ at $4 \mathrm{~A} \mathrm{~g}^{-1}$ )

Specific capacity $(920$, $501,141 \mathrm{mAh}$ $\mathrm{g}^{-1}$ at $0.1,0.5$, $2.5 \mathrm{~A} \mathrm{~g}^{-1}$, respectively)

Specific capacity (1672, $915 \mathrm{mAh} \mathrm{g}^{-1}$ at $0.1,10 \mathrm{~A} \mathrm{~g}^{-1}$, respectively)

Capacity (1010, $580,495 \mathrm{mAh}$ $\mathrm{g}^{-1}$ at $0.2,0.5,5$

$$
\mathrm{A} \mathrm{g}^{-1} \text {, }
$$

respectively)

Specific capacity (610 $\mathrm{mAh} \mathrm{g}^{-1}$ at $5 \mathrm{C}$ )

Specific capacity $(827.9$ $\mathrm{mAh} \mathrm{g}^{-1}$ at 2.01

$$
\mathrm{A} \mathrm{g}^{-1} \text { ) }
$$

Specific capacity (320 $\mathrm{mAh} \mathrm{g}^{-1}$ at $1 \mathrm{C}$ for $\mathrm{TiO}_{2} / \mathrm{CNT}$; $\sim 580 \mathrm{mAh} \mathrm{g}^{-1}$ for $\mathrm{SnO}_{2} / \mathrm{CNT}$ at $0.4 \mathrm{~A} \mathrm{~g}^{-1}$ )

$100.6 \%$ retained after 1000 cycles at $1 \mathrm{~A} \mathrm{~g}^{-1}$

$566 \mathrm{mAh} \mathrm{g}^{-1}$ is retained after 50 cycles at $0.5 \mathrm{~A} \mathrm{~g}^{-1}$

$80.2 \%$ retained after 500 cycles at $0.5 \mathrm{~A} \mathrm{~g}^{-1}$

$92.3 \%$ retained after 2000 cycles at $10 \mathrm{~A} \mathrm{~g}^{-1}$

Increased to 648 $\mathrm{mAh} \mathrm{g}^{-1}$ after 680 cycles at 0.5

$$
\mathrm{A} \mathrm{g}^{-1}
$$

$>97 \%$ retained after 150 cycles at $1 \mathrm{C}$

$96 \%$ retained after 425 cycles at $1 \mathrm{~A} \mathrm{~g}^{-1}$

93.8\% retained after 120 cycles at $1 \mathrm{C}$ for $\mathrm{TiO}_{2} / \mathrm{CNT}$; $\sim 72.4 \%$ retained after 40 cycles at $0.4 \mathrm{~A} \mathrm{~g}^{-1}$ for $\mathrm{SnO}_{2} / \mathrm{CNT}$

$$
\begin{array}{cc}
\text { Volumetric } & \text { Increased from } \\
\text { capacitance } & 320 \text { to } 430 \mathrm{mAh} \\
\left(325 \mathrm{~F} \mathrm{~cm}^{-3} \text { at } 5\right. & \mathrm{g}^{-1} \text { after } 300
\end{array}
$$


$\mathrm{Na}_{3} \mathrm{~V}_{2}\left(\mathrm{PO}_{4}\right)_{3} / \mathrm{C}$

\section{Carbon-coated silicene}

Nitrogen-doped carbon coated $\mathrm{Li}_{4} \mathrm{Ti}_{5} \mathrm{O}_{12}$

$\mathrm{MoS}_{2} /$ carbon nanofibers

$\mathrm{MoS}_{2} / \mathrm{N}$-doped carbon nanoboxes

$\mathrm{Na}_{0.66} \mathrm{Li}_{0.18} \mathrm{Mn}_{0.71} \mathrm{Ni}_{0.21} \mathrm{Co}_{0.08} \mathrm{O}_{2+\delta}$

$\mathrm{MoS}_{2}$

Phosphorene-graphene

SnS@RGO

$\mathrm{SnS}_{2} / \mathrm{RGO}$

$\mathrm{MoS}_{2} / \mathrm{RGO}$ carbonate

$1 \mathrm{M} \mathrm{LiPF}_{6}$ in a $1: 1(\mathrm{v} / \mathrm{v})$ mixture of ethylene carbonate and dimethyl carbonate

$1 \mathrm{M} \mathrm{LiPF}_{6}$ in a $1: 1(\mathrm{v} / \mathrm{v})$ mixture of ethylene carbonate and dimethyl carbonate

1.3 $\mathrm{M} \mathrm{LiPF}_{6}$ in a mixture of 3:7 (v/v) ethylene carbonate/diethyl carbonate with $10 \mathrm{wt} \%$ fluorinated ethylene carbonate

$1 \mathrm{M} \mathrm{LiPF}_{6}$ in a $1: 1$ mixture of ethylene carbonate and dimethyl carbonate

$1 \mathrm{M} \mathrm{LiPF}_{6}$ in ethylene carbonate/dimethyl carbonate/diethyl carbonate $\left(1: 1: 1\right.$ in $\left.w t^{\%}\right)$

$1 \mathrm{M} \mathrm{LiPF}_{6}$ in a $1: 1(\mathrm{w} / \mathrm{w})$ mixture of ethylene carbonate and diethyl carbonate

$1 \mathrm{M} \mathrm{NaPF}_{6}$ in a $1: 1(\mathrm{v} / \mathrm{v})$ mixture of ethylene carbonate and diethyl carbonate

$1 \mathrm{M} \mathrm{NaClO}_{4}$ in a $1: 1(\mathrm{v} / \mathrm{v})$ mixture of ethylene carbonate and propylene carbonate

$1 \mathrm{M} \mathrm{NaPF}_{6}$ in a mixture of ethylene carbonate and diethyl carbonate with $10 \%$ fluoroethylene carbonate

$1 \mathrm{M} \mathrm{NaClO}_{4}$ in a $1: 1(\mathrm{v} / \mathrm{v})$ mixture of ethylene carbonate and propylene carbonate with $5 \mathrm{wt} \%$ fluoroethylene carbonate

$1 \mathrm{M} \mathrm{NaClO}_{4}$ in a $1: 1(\mathrm{v} / \mathrm{v})$ mixture of ethylene carbonate and diethyl carbonate

$1 \mathrm{M} \mathrm{NaClO}_{4}$ in a $1: 1(\mathrm{v} / \mathrm{v})$ mixture of ethylene carbonate and dimethyl
LIBs

$\mathrm{mV} \mathrm{s}^{-1}$ )

cycles at $2.5 \mathrm{C}$

Specific

capacity (544 $\mathrm{mAh} \mathrm{g}{ }^{-1}$ at 10

$$
\mathrm{A} \mathrm{g}^{-1} \text { ) }
$$

Specific capacity (230 $\mathrm{mAh} \mathrm{g}^{-1}$ at 0.91

C)

LIBs

Specific capacity $(865$ $\mathrm{mAh} \mathrm{g}^{-1}$ at $1 \mathrm{~A}$

$$
\mathrm{g}^{-1} \text { ) }
$$

Increased capacity after 100 cycles at 0.5

$$
\mathrm{A} \mathrm{g}^{-1}
$$

$83.6 \%$ retained after 5000 cycles at $9.1 \mathrm{C}$

92.3, 91.7\% retained after 500 cycles at 0.5 , $1 \mathrm{C}$, respectively

LIBs

\section{Specific} capacity $(170$ $131 \mathrm{mAh} \mathrm{g}^{-1}$ at $1,10 \mathrm{C}$, respectively)

LIBs

Specific capacity (864 $\mathrm{mAh} \mathrm{g}^{-1}$ at $5 \mathrm{~A}$

$$
\mathrm{g}^{-1} \text { ) }
$$

LIBs

Specific capacity (689, 531, $403 \mathrm{mAh}$ $\mathrm{g}^{-1}$ at $2,4,8 \mathrm{~A}$ $\mathrm{g}^{-1}$, respectively)

SIBs

Discharge capacity (134 $\mathrm{mAh} \mathrm{g}^{-1}$ at $1 \mathrm{C}$ )

SIBs

Specific capacity (530 $\mathrm{mAh} \mathrm{g}^{-1}$ at 0.04

$$
\mathrm{A} \mathrm{g}^{-1} \text { ) }
$$

SIBs

\section{Capacity (2440,} 2320, 1450, $1200,915,645$ $\mathrm{mAh} \mathrm{g}^{-1}$ at $0.02,0.08,3$, 4.6, 7.7, $10 \mathrm{C}$, respectively)

SIBs

Specific capacity (940 $\mathrm{mAh} \mathrm{g}^{-1}$ at 0.03

$$
\mathrm{A} \mathrm{g}^{-1} \text { ) }
$$

SIBs

Specific capacity (630, $544 \mathrm{mAh} \mathrm{g}^{-1}$ at $0.2,2 \mathrm{~A} \mathrm{~g}^{-1}$, respectively)

SIBs

Discharge capacity (385 $\mathrm{mAh} \mathrm{g}^{-1}$ at 1.5
No obvious deterioration over 100 cycles at $10 \mathrm{C}$

Slightly decease after 300 cycles at $1 \mathrm{~A} \mathrm{~g}^{-1}$

$952 \mathrm{mAh} \mathrm{g}^{-1}$ is retained after 200 cycles at 0.4

$$
\mathrm{A} \mathrm{g}^{-1}
$$

$84 \%$ retainted after 50 cycles at $0.2 \mathrm{C}$ and $75 \%$ retained after 150 cycles at $0.5 \mathrm{C}$

330, 305, 251 $\mathrm{mAh} \mathrm{g}^{-1}$ is retained after 100 cycles at $0.08,0.16,0.32$ $\mathrm{A} \mathrm{g}^{-1}$, respectively

$84 \%$ retained after 100 cycles at $3 \mathrm{C}$

492, $308 \mathrm{mAh} \mathrm{g}^{-}$ ${ }^{1}$ is retained after 250 cycles at $0.81,7.29 \mathrm{~A} \mathrm{~g}^{-1}$, respectively

$500 \mathrm{mAh} \mathrm{g}^{-1}$ is retained after 400 cycles at $1 \mathrm{~A}$ $\mathrm{g}^{-1}$

$84 \%$ retained after 600 cycles 
carbonate with $5 \mathrm{wt} \%$

fluoroethylene carbonate

182

$\mathrm{MoS}_{2} / \mathrm{RGO}$

184
$\mathrm{MoS}_{2} / \mathrm{Ni}_{3} \mathrm{~S}_{2} @ \mathrm{MoS}_{2}$ on 3D

$\mathrm{Ni}$ graphene foam
$1 \mathrm{M} \mathrm{NaClO}_{4}$ in a $1: 1(\mathrm{v} / \mathrm{v})$ mixture of ethylene

carbonate and propylene carbonate
$1 \mathrm{M} \mathrm{NaPF}_{6}$ in a $1: 1(\mathrm{v} / \mathrm{v})$ mixture of ethylene carbonate and diethyl carbonate with 3 vol\% fluoroethylene carbonate

\section{WILEY-VCH}

$\left.\mathrm{A} \mathrm{g}^{-1}\right)$

SIBs

Specific capacity $(352$ $\mathrm{mAh} \mathrm{g}^{-1}$ at 0.64 $\mathrm{A} \mathrm{g}^{-1}$ )

SIBs

Specific capacity $(568$, $0.2,5 \mathrm{~A} \mathrm{~g}^{-1}$, respectively) at $1.5 \mathrm{~A} \mathrm{~g}^{-1}$

254, $227 \mathrm{mAh} \mathrm{g}^{-}$ ${ }^{1}$ is retained after

300 cycles at $0.08,0.32 \mathrm{~A} \mathrm{~g}^{-1}$, respectively

$207 \mathrm{mAh} \mathrm{g}^{-1}$ is retained after 400 cycles at $5 \mathrm{~A}$ $\mathrm{g}^{-1}$

RGO-reduced graphene oxide; CNT-carbon nanotube 